\title{
Diagnosis, grading and management of toxicities from immunotherapies in children, adolescents and young adults with cancer
}

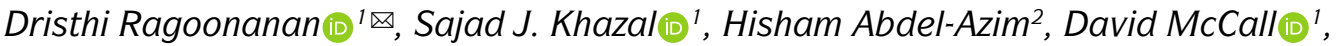
Branko Cuglievan ${ }^{1}$, Francesco Paolo Tambaro 3 , Ali Haider Ahmad', Courtney M. Rowan', Cristina Gutierrez ${ }^{5}$, Keri Schadler ${ }^{6}$, Shulin $\mathrm{Li}^{7}$, Matteo Di Nardo ${ }^{8}$, Linda Chi ${ }^{9}$, Alison M. Gulbis ${ }^{10}$, Basirat Shoberu ${ }^{1}$, Maria E. Mireles ${ }^{10}$, Jennifer McArthur ${ }^{11,12}$, Neena Kapoor ${ }^{2}$, Jeffrey Miller ${ }^{1}$, Julie C. Fitzgerald $\mathbb{1}^{13}$, Priti Tewari ${ }^{1}$, Demetrios Petropoulos ${ }^{1}$, Jonathan B. Gill', Christine N. Duncan ${ }^{14}$, Leslie E. Lehmann ${ }^{14}$, Sangeeta Hingorani ${ }^{15}$, Joseph R. Angelo ${ }^{16}$, Rita D. Swinford ${ }^{17}$, Marie E. Steiner ${ }^{18}$, Fiorela N. Hernandez Tejada ${ }^{1}$, Paul L. Martin ${ }^{19}$, Jeffery Auletta ${ }^{20}$, Sung Won Choi ${ }^{21}$, Rajinder Bajwa ${ }^{22}$, Natalie Dailey Garnes (10 ${ }^{23}$, Partow Kebriaei24, Katayoun Rezvani24, William G. Wierda ${ }^{25}$, Sattva S. Neelapu (10 ${ }^{26}$, Elizabeth J. Shpall ${ }^{24}$, Selim Corbacioglu ${ }^{27}$ and Kris M. Mahadeo (1)

Abstract | Cancer immunotherapies are associated with remarkable therapeutic response rates but also with unique and severe toxicities, which potentially result in rapid deterioration in health. The number of clinical applications for novel immune effector-cell therapies, including chimeric antigen receptor (CAR)-expressing cells, and other immunotherapies, such as immune-checkpoint inhibitors, is increasing. In this Consensus Statement, members of the Pediatric Acute Lung Injury and Sepsis Investigators (PALISI) Network Hematopoietic Cell Transplantation-Cancer Immunotherapy (HCT-Cl) Subgroup, Paediatric Diseases Working Party (PDWP) of the European Society of Blood and Marrow Transplantation (EBMT), Supportive Care Committee of the Pediatric Transplantation and Cellular Therapy Consortium (PTCTC) and MD Anderson Cancer Center CAR T Cell Therapy-Associated Toxicity (CARTOX) Program collaborated to provide updated comprehensive recommendations for the care of children, adolescents and young adults receiving cancer immunotherapies. With these recommendations, we address emerging toxicity mitigation strategies, we advocate for the characterization of baseline organ function according to age and discipline-specific criteria, we recommend early critical care assessment when indicated, with consideration of reversibility of underlying pathology (instead of organ failure scores) to guide critical care interventions, and we call for researchers, regulatory agencies and sponsors to support and facilitate early inclusion of young patients with cancer in well-designed clinical trials.

Cancer immunotherapies harness components of the immune system to induce long-term cancer remission. Immunotherapeutic agents include immune-checkpoint inhibitors (ICIs), bispecific T cell engagers (BiTEs) and immune-effector cells (IECs), which have all revolutionized oncology in the past decade. Nevertheless, these therapies have been associated with unique and potentially life-threatening toxicities, which include cytokine-release syndrome (CRS), IEC-associated neurotoxicity syndrome (ICANS) and other severe immune-related adverse events (irAEs). Vigilance, prompt recognition and management of these toxicities, with attention to age-appropriate considerations, can lead to optimized outcomes in children and in adolescents and young adults (AYAs) receiving these therapies. Paediatric populations are defined as those 
including patients aged $<15$ years, and AYA populations include patients aged $15-25$ years $^{1}$. We have previously published grading and management guidelines for paediatric patients receiving IEC-based therapy with chimeric antigen receptor (CAR) $\mathrm{T}$ cells ${ }^{2}$, and the American Society for Transplantation and Cellular Therapy (ASTCT) subsequently adopted key elements of the grading criteria that we developed but has not proposed management guidelines ${ }^{3}$.

In 2020, the Pediatric Acute Lung Injury and Sepsis Investigators (PALISI) Network Hematopoietic Cell Transplantation-Cancer Immunotherapy Subgroup

\footnotetext{
Author addresses

1Department of Pediatrics, CARTOX Program, The University of Texas MD Anderson

Cancer Center, Houston, TX, USA.

${ }^{2}$ Department of Pediatrics, Blood and Marrow Transplantation Program, Keck School of

Medicine, University of Southern California, Children's Hospital Los Angeles, Los Angeles, CA, USA.

${ }^{3}$ UOC SIT-TMO AORN Santobono-Pausilipon, Napoli, Italy.

${ }^{4}$ Department of Pediatrics, Division of Critical Care, Indiana University School of

Medicine, Riley Hospital for Children, Indianapolis, IN, USA.

${ }^{5}$ Department of Critical Care, The University of Texas MD Anderson Cancer Center,

Houston, TX, USA.

${ }^{6}$ Department of Pediatrics Research, Center for Energy Balance in Cancer Prevention and Survivorship, The University of Texas MD Anderson Cancer Center, Houston, TX, USA.

${ }^{7}$ Department of Pediatrics Research, The University of Texas MD Anderson Cancer Center, Houston, TX, USA.

${ }^{8}$ Pediatric Intensive Care Unit, Bambino Gesù Children's Hospital, IRCCS, Rome, Italy. 'Division of Diagnostic Imaging, Neuroradiology Department, The University of Texas MD

Anderson Cancer Center, Houston, TX, USA.

${ }^{10}$ Division of Pharmacy, The University of Texas MD Anderson Cancer Center, Houston,

TX, USA.

${ }^{11}$ Department of Pediatrics, Division of Critical Care, St Jude Children's Research Hospital, Memphis, TN, USA.

${ }^{12}$ Department of Pediatrics, Division of Critical Care, Medical College of Wisconsin,

Milwaukee, WI, USA.

${ }^{13}$ Department of Anesthesia and Critical Care, University of Pennsylvania Perelman

School of Medicine, The Children's Hospital of Philadelphia, Philadelphia, PA, USA.

${ }^{14}$ Pediatric Hematology-Oncology, Dana-Farber Cancer Institute, Harvard University,

Boston, MA, USA.

${ }^{15}$ Department of Pediatrics, University of Washington School of Medicine, Division of

Nephrology, Seattle Childrens and the Clinical Research Division, Fred Hutchinson

Cancer Research Center, Seattle, WA, USA.

${ }^{16}$ Renal Section, Baylor College of Medicine, Texas Children's Hospital, Houston, TX, USA.

${ }^{17}$ Department of Pediatrics, Division of Pediatric Nephrology, McGovern Medical School,

The University of Texas Health Science Center, Houston, TX, USA.

${ }^{18}$ Department of Pediatrics, University of Minnesota, Minneapolis, MN, USA.

${ }^{19}$ Department of Pediatrics, Division of Transplant and Cellular Therapy, Duke Children's

Hospital, Duke University, Durham, NC, USA.

${ }^{20}$ Division of Hematology, Oncology, Bone Marrow Transplant and Infectious Diseases,

Nationwide Children's Hospital, Ohio State University, Columbus, OH, USA.

${ }^{21}$ Department of Pediatrics, University of Michigan, Ann Arbor, MI, USA.

${ }^{22}$ Division of Pediatric Hematology/Oncology/Blood and Marrow Transplantation,

Nationwide Children's Hospital, The Ohio State University, Columbus, OH, USA.

${ }^{23}$ Department of Infectious Disease, The University of Texas MD Anderson Cancer Center,

Houston, TX, USA.

${ }^{24}$ Department of Stem Cell Transplantation and Cellular Therapy, CARTOX Program,

The University of Texas MD Anderson Cancer Center, Houston, TX, USA.

${ }^{25}$ Department of Leukemia, The University of Texas MD Anderson Cancer Center,

Houston, TX, USA.

${ }^{26}$ Department of Lymphoma and Myeloma, CARTOX Program, The University of Texas MD

Anderson Cancer Center, Houston, TX, USA.

${ }^{27}$ Department of Pediatric Hematology, Oncology and Stem Cell Transplantation,

University of Regensburg, Regensburg, Germany.
}

and the MD Anderson Cancer Center CAR T Cell Therapy-Associated Toxicity (CARTOX) Program convened an interdisciplinary and international expert panel of key opinion leaders from leading academic centres and societies, including the Paediatric Diseases Working Party of the European Society of Blood and Marrow Transplantation, the Supportive Care Committee of the Pediatric Transplantation and Cellular Therapy Consortium and the Extracorporeal Life Support Organization, with three aims: (1) to assess the current state of cancer immunotherapy for paediatric patients; (2) to provide interdisciplinary supportive care guidelines for these patients; and (3) to develop proactive surveillance strategies for possible late effects related to these treatments. The panellists included physicians, fellows, trainees, nurses, pharmacists and basic and translational scientists with expertise in paediatric and adult immunotherapy, haematology, solid tumour, nephrology, critical care and infectious disease. New immunotherapies with unique toxicity profiles continue to emerge; herein, we provide recommendations applicable to the management of children and AYAs receiving these therapies (BOX 1).

\section{Methods}

Panellists conducted literature reviews using key specific search teams ('cancer immunotherapies', 'tumourinfiltrating lymphocyte,' 'T cell receptor therapy', 'natural killer cell therapy', 'virus-specific cytotoxic lymphocyte,' 'bispecific T cell engager', 'immune-checkpoint inhibitor', 'chimeric antigen receptor T cell therapy', 'cytokine-release syndrome', 'immune effector cellassociated neurotoxicity syndrome', 'haemophagocytic lymphohistiocytosis', 'immune-related adverse event', 'pseudoprogression' and 'infection prophylaxis') that were summarized and reviewed by a writing committee (see Author contributions). The guideline panel comprised a multidisciplinary and interprofessional team, including physicians with expertise in paediatrics, IEC therapy, immunotherapy and ICIs. A modified Delphi method was used to vote until consensus was achieved by all panellists via electronic communications. The final manuscript was reviewed and approved by all authors as well as the Scientific Review Committee of the PALISI Network.

\section{Cancer immunotherapies}

CAR-transduced cell therapies. CAR T cells are generated through genetic modification of the patient's own (autologous) $\mathrm{T}$ cells or $\mathrm{T}$ cells from an allogeneic donor. In 2017, tisagenlecleucel was the first CAR T cell product to be approved by the FDA for the treatment of patients aged $<25$ years with relapsed and/or refractory $(\mathrm{R} / \mathrm{R})$ $\mathrm{CD} 19^{+} \mathrm{B}$ cell acute lymphoblastic leukaemia (B-ALL) ${ }^{4}$. Shortly after, axicabtagene ciloleucel was also approved by the FDA for the treatment of adult patients with R/R large B cell lymphomas, and in 2020, brexucabtagene autoleucel was approved for the treatment of adult patients with $\mathrm{R} / \mathrm{R}$ mantle cell lymphoma ${ }^{5,6}$. These therapies can result in remarkable clinical outcomes, but are also associated with unique and potentially fatal toxicities, such as CRS and ICANS ${ }^{7}$. Specific toxicity profiles can differ 


\section{Box $1 \mid$ Key consensus recommendations}

- By definition, cancers in children and in adolescents and young adults (AYAs) are rare cancers and, therefore, these populations should be included in well-designed clinical trials at the earliest time point possible. We encourage researchers, sponsors, institutions, regulatory agencies and payors to facilitate enrolment of these patients in trials.

- Cytokine-release syndrome (CRS) and immune effector cell-associated neurotoxicity syndrome (ICANS) should be graded following American Society for Transplantation and Cellular Therapy (ASTCT) criteria ${ }^{3}$. Health-care institutions are encouraged to regularly review management guidelines on the basis of current evidence, as well as host and product variables. Early initiation of cytokine blockade therapies to mitigate toxicity should be considered (FICS 1 and 2).

- Characterization of baseline organ function according to discipline-specific guidelines could facilitate monitoring of outcomes as well as toxicities from immunotherapy and foster collaborative research aimed at enhancing long-term outcomes. When possible, baseline comprehensive organ assessments should be performed, including neuroimaging, neurodevelopmental assessment, Cornell Assessment of Paediatric Delirium (CAPD) scoring, Kidney Disease: Improving Global Outcomes Work Group (KDIGO) renal assessment, and cardiac and pulmonary assessments.

- Serial monitoring of corticotropin, thyrotropin, luteinizing hormone and folliclestimulating hormone might be indicated in children receiving immune-checkpoint inhibitors ( $\mathrm{ICls}$ ), ideally at baseline, 2 weeks after treatment initiation and then every 4-6 weeks. Deviation from age-appropriate physiologically normal values might indicate the need for radiographic imaging, hormone replacement, steroid administration, beta blockers, paediatric endocrinology evaluation and/or inpatient admission (for more extensive clinical assessments).

- Consider critical care assessment as early as possible, in particular in patients with grade $\geq 3$ toxicities.

- Reversibility of underlying pathology, and not organ failure scores, should guide decisions about limiting critical care support.

- Monitoring of graft-versus-host disease (GVHD) in patients receiving allogeneic immune effector cell (IEC) products should follow paediatric grading, staging and management guidelines (Supplementary Table 1).

- Age-appropriate criteria should be used to assess toxicities from IEC or other immunotherapies in children. Aspects to assess include age-appropriate vital signs, estimation of body surface area (using methods such as Lund-Browder charts), renal (KDIGO) and endocrine function, and stool output. Age-appropriate mood disorder and libido assessment should be performed to screen for hypophysitis (TABLE 2).

- High vigilance for early toxicities is warranted in children and AYAs receiving $\mathrm{ICls}$ (as early as the first cycle).

- Children and AYAs receiving cancer immunotherapies should have baseline infectious disease evaluations and receive appropriate prophylaxis, with attention to age-appropriate monitoring of response to therapy (Supplementary Tables 2 and 3 ).

- All patients should be offered seasonal influenza vaccinations unless a specific contraindication exists (Supplementary Table 2).

- Revaccination or antibody titre testing should be considered 6 months after administration of antibodies targeting B cell markers or ICls. At present there are no standard recommendations regarding vaccination of paediatric and AYA patients treated with CAR T cell therapy (Supplementary Table 2).

- Protocols for cancer immunotherapy eligibility and COVID-19 prevention including vaccination, screening and management should be established locally and reviewed regularly in the context of infectious epidemiology and available resources.

- Interdisciplinary and frontline staff should demonstrate and maintain competency in prompt recognition and management of complications from immunotherapy in children and AYAs, with clinical algorithms available for rapid escalation of care when indicated. Interprofessional simulation training might help to cultivate a collaborative team approach, and to establish and maintain competency.

depending on: (1) the source cell type (typically T cells or natural killer (NK) cells); (2) the engineered product (including the target antigen, costimulatory domain and gene transfer technology); (3) the manufacturing process and reagents; (4) the primary disease; and (5) host factors, specific details of which are beyond the scope of this Consensus Statement ${ }^{8-10}$.

Resistance to CAR T cell therapy, including in the context of variations in antigen expression levels, warrants further research. Dual targeting of tumour cell-surface markers (such as CD19 and CD20) might help overcome treatment failure owing to downregulation of single antigen targets ${ }^{11}$. Fousek et al. created a trivalent CAR T cell product targeting CD19, CD20 and $\mathrm{CD} 22$ that was associated with promising preclinical results and is pending study in trials involving patients with $\mathrm{CD} 19^{-}$relapsed B cell lineage disease ${ }^{12,13}$.

Next-generation IEC products, which could be used in new disease indications and could potentially be associated with more durable disease remissions and reduced toxicity, are the topic of investigation in current clinical trials, some involving children and AYAs

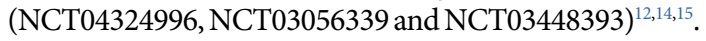
UCART19 is an allogeneic 'off-the-shelf' gene-edited CD19-targeted CAR T cell product, in which TRAR2 expression was deleted to abrogate the potential induction of graft-versus-host disease (GVHD) by donor $\mathrm{T}$ cells ${ }^{16}$. In two multicentre phase I trials involving 7 children and 14 adults with R/R B-ALL, two patients treated with UCART19 developed GVHD (manifested as grade 1 skin toxicity). Other reported AEs included grade 3-4 CRS in three patients, grade 1-2 ICANS in eight patients and grade 4 prolonged cytopenias in six patients. Of the 21 patients, 14 had complete responses with or without incomplete haematological recovery at 28 days after infusion, with a median duration of response of 4.1 months. The use of allogeneic CAR NK cells has also been proposed to potentially minimize the risk of GVHD; one such approach is being tested in a trial including children with $\mathrm{R} / \mathrm{R} \mathrm{CD19}{ }^{+}$haematological cancers $^{14}$.

TIL therapies. The tumour microenvironment (TME) typically contains tumour-infiltrating lymphocytes (TILs), including cytotoxic $\left(\mathrm{CD}^{+}\right)$and helper $\left(\mathrm{CD}^{+}\right) \mathrm{T}$ cells, $B$ cells and NK cells, which can all influence metastasis, relapse and treatment response ${ }^{17-19}$. While most immune cells residing in the TME are functionally impaired, TILs can be harnessed as a form of adoptive cell therapy through the ex vivo expansion of resident $\mathrm{T}$ cells harvested from a patient's tumour ${ }^{20}$. TIL production typically takes several weeks using the existing rapid expansion protocols for selected TIL lines with the best in vitro tumour reactivity ${ }^{21}$. Lymphodepletion with fludarabine and cyclophosphamide, sometimes in conjunction with total body irradiation, potentiates the antitumour effect of TILs by limiting regulatory cells and eliminating cell subpopulations that compete with them for cytokines and $\mathrm{T}$ cell growth factors ${ }^{21-24}$. TILs are typically infused with high-dose IL-2, an approach consistently associated with promising objective response rates in patients with metastatic melanoma ${ }^{24-26}$. Current research efforts in this field are focused on expanding indications, optimizing selection of T cell subsets, defining the choice of preparative lymphodepleting and/or IL-2 regimens. 
A high neoantigen burden has been associated with increased presence of neoantigen-reactive TILs as well as improved responses to ICIs. Neoantigen burden has been suggested to be closely related to the presence of non-synonymous single-nucleotide variants (nsSNVs), which varies substantially across cancer types (from one nsSNV per tumour in paediatric tumours to $>1,500$ nsSNVs per tumour in tumours associated with high microsatellite instability $)^{27,28}$. An enrichment in indel frameshift mutations has also been associated with a high burden of neoantigens that are distinct from self $f^{28}$. Identification of neoantigen-reactive TILs based on the presence of nsSNVs and indel mutations has improved and might constitute a promising approach to improving the efficiency of therapies involving TILs ${ }^{28}$.

TIL-based therapies have been explored in some cancers that predominantly affect children, such as neuroblastoma. TILs have been successfully expanded from tumour samples obtained through either biopsy or resection from children with neuroblastoma. Substantial numbers of NK T (NKT) cells and $\gamma \delta \mathrm{T}$ cells were identified alongside the mixed population of $\mathrm{CD}^{+}$and $\mathrm{CD} 4^{+} \mathrm{T}$ cells with either effector or central memory phenotypes ${ }^{29}$. Transduction of TILs with a second-generation CAR targeting GD2 enhanced elimination of neuroblastoma cells in vitro ${ }^{29}$. Researchers have hypothesized that neoadjuvant treatment with ICIs in children with neuroblastoma could result in enrichment of tumour tissue with lymphocytes. These TILs could be expanded rapidly ex vivo during a short interval between surgery and infusion in order to achieve a suitable target cell dose for adoptive transfer ${ }^{29}$. Neoadjuvant treatment with anti-CTLA4 antibodies has been proven to be feasible and well tolerated in adults with metastatic melanoma ${ }^{30}$.

The presence of $\mathrm{CD}^{+} \mathrm{T}$ cells in tumours does not guarantee tumour eradication because they might have an exhausted and/or inactive phenotype. The IFN $\gamma^{\mathrm{Hi}} \mathrm{CD} 8{ }^{\mathrm{Hi}} \mathrm{FOXP} 3^{\text {Low }} \mathrm{CD} 33^{\text {Low }}$ immune profile in tumours has been shown to be an excellent prognostic marker for favourable overall survival (OS) across patients with various tumour types ${ }^{31}$. Treatment with tumour cell-surface vimentin-targeted IL-12 (ttIL-12) before surgery converted tumours to this favourable IFN $\gamma^{\mathrm{Hi}} \mathrm{CD} 8^{\mathrm{Hi}} \mathrm{FOXP} 3^{\text {Low }} \mathrm{CD} 33^{\text {Low }}$ immune profile, leading to prolonged OS compared with no treatment or treatment with wild-type IL-12 in both mouse and patient-derived xenograft models ${ }^{31}$. The levels of serum IL-12 were lower in mice receiving ttIL- 12 than in those receiving IL-12, which might have been associated with reduced toxicity ${ }^{31}$. Similarly, IL-2 can enhance the inherent antitumour activity of $\mathrm{CD}^{+} \mathrm{T}$ cells and the cytolytic function of NK cells, but is also associated with a variety of toxicities, including capillary leak syndrome (CLS), characterized by oedema, hypotension and oliguria within hours of infusion, fevers, rigors, myalgia and nausea ${ }^{21,32}$. In a study involving paediatric patients with progressive or metastatic tumours treated with IL-2, two of ten patients had CLS, three patients had grade 3-4 hypotension and all had fever, headache and bone and muscle pain ${ }^{33}$. TIL-related toxicities are less common, but can include mostly transient, dyspnoea, rigors and fever shortly after infusion. Autoimmune sequelae, including panuveitis, hearing loss and vitiligo, have been reported with adoptive cell transfer of TILs targeting melanoma-associated antigens ${ }^{34}$.

Engineered TCR therapies. Engineered T cell receptor (TCR) therapy involves the infusion of T cells previously extracted from the blood of a patient and genetically modified to express: (1) receptors that recognize cancerspecific antigens, improve T cell survival and migration and/or reduce tumour-induced immune escape; and/or (2) cytokines to enhance T cell survival and tumour infiltration. AEs might be dependent on the antigen targeted, the methods used to engineer the TCR and the affinity of the transduced TCR ${ }^{8,9}$.

In a phase I trial, a TCR targeting a HLA-A ${ }^{\star} 0201$ restricted NY-ESO-1 epitope, a highly immunogenic protein aberrantly expressed in several tumour types, OS at 3 and 5 years was $38 \%$ and $14 \%$ in adults and AYAs with synovial cell sarcoma, respectively, and $33 \%$ at both time points in those with melanoma ${ }^{35}$. All patients had transient toxicities, which were deemed to be associated with administration of the conditioning regimen and/or IL-2. A treatment-related death occurred 3 days after $\mathrm{T}$ cell infusion in a patient who had developed neutropenia and had septic shock from Escherichia coli bacteraemia ${ }^{35}$.

Severe central nervous system (CNS) toxicities, including necrotizing leukoencephalopathy, coma and treatment-related mortality, have been reported in adults and AYAs with melanoma receiving $\mathrm{T}$ cells with engineered TCRs targeting MAGEA3, owing to cross-recognition of MAGEA12 expressed in the $\mathrm{CNS}^{36}$. Cross-recognition of an unrelated epitope also resulted in cardiogenic shock and death in two adults (one with melanoma and the other with multiple myeloma) who received $\mathrm{T}$ cells with engineered TCRs targeting MAGEA3 ( $\mathrm{REF}^{37}$ ). In another trial involving adults with metastatic melanoma, treatment with $\mathrm{T}$ cells expressing engineered TCRs targeting MART-1 and gp100 led to 'on-target, off-tumour' effects including skin rash (requiring treatment with local steroid injections), uveitis, hearing impairment and CRS (that led to respiratory failure and required the use of systemic steroids) ${ }^{38}$. No serious AEs occurred in eight adult patients with acute myeloid leukaemia or myelodysplastic syndrome who received T cells with engineered TCRs targeting WT1 $\left(\mathrm{REF}^{39}\right)$. Ongoing clinical trials are testing engineered TCR therapies in children with haematological malignancies (NCT03326921) or solid tumours (NCT03240861).

NK cell therapies. Infusion of NK cells has emerged as a promising immunotherapy approach because these highly cytotoxic immune effector lymphocytes are capable of eliminating their target cells in an HLA-unrestricted fashion ${ }^{40}$. NK cells can either directly kill tumour cells through the release of cytoplasmic granules that contain perforin and granzyme, which results in target cell apoptosis, or through the expression of membranebound ligands that trigger NK cell cytolytic activity upon interacting with their receptors on target cells ${ }^{40-42}$. 
Khatua et al. reported the feasibility of locoregional administration of expanded NK cells in nine children with R/R medulloblastoma or ependymoma ${ }^{41}$. Among these patients, eight had AEs defined as grade 1-2 according to the Common Terminology Criteria for Adverse Events (CTCAE) v5.0, including headache, fatigue and thrombocytopenia. One patient had CTCAEv5.0-defined grade 3 slurred speech that resolved with a short course of steroids and was unlikely to have been related to NK cell administration ${ }^{41}$. In a study involving 18 children and AYAs with R/R ALL, NK cells from haploidentical donors were well tolerated, with no reported GVHD ${ }^{43}$. In that cohort, ten patients proceeded to haematopoietic stem cell transplantation (HSCT) and, at the time of writing, almost half had achieved a durable remission ${ }^{43}$. Other studies of NK cells in patients with leukaemia have shown promising results and suggest that NK cell dosing might be an important determinant of therapeutic response and disease outcome $\mathrm{e}^{44,45}$.

Cell lines derived from paediatric solid tumours, such as osteosarcoma, Ewing sarcoma and rhabdomyosarcoma, are sensitive to NK cells ${ }^{46,47}$. In a first-inhuman trial of donor-derived NK cells after allogeneic HSCT in AYAs and adults with solid tumours, acute GVHD occurred in five of nine patients, and four patients had a durable remission following HSCT ${ }^{48}$. Pérez-Martínez et al. reported a possible graft versus tumour effect from donor NK cell populations among six children with solid tumours who underwent haploidentical HSCT with a reported disease-free survival of $50 \%$ after a median follow-up duration 14 months ${ }^{49}$.

The efficacy of NK cell therapy might be constrained by the finite lifespan of NK cells, the immunosuppressive nature of the TME of solid tumours and, until the last decade, limitations of ex vivo large-scale NK cell expansion methods ${ }^{50,51}$. These obstacles could be overcome through genetic modification to introduce co-stimulatory domains and/or antigen specificity through CAR. Additionally, cord blood-derived NK cells might be a readily available source of off-the-shelf products. In a phase I/II study of ex vivo expanded allogeneic cord blood-derived NK cells in children and AYAs with solid tumours, no dose-limiting toxicities and/or GVHD have been reported to date (NCT03420963).

Virus-specific cytotoxic lymphocytes. Studies of multiple malignancies, including melanoma and lymphoma, have provided clear evidence that cytotoxic lymphocytes (CTLs; $\mathrm{CD}^{+}$cells) are involved in clinical progression ${ }^{52}$. Van Pel and Boon demonstrated that the lack of immunogenicity of a tumour reflects an inability to activate the immune system rather than the absence of tumour antigens $^{53}$. CD ${ }^{+}$CTLs alone or in combination with $\mathrm{CD}^{+}$ cells help to mount an antitumour immune response $\mathrm{e}^{54}$. Epstein-Barr virus (EBV)-associated lymphoproliferative disorders unequivocally result from $\mathrm{T}$ cell dysfunction in immunosuppressed individuals, in particular, after HSCT and/or relapse after standard-of-care therapies (such as rituximab); expanded EBV-specific CTLs present a promising new therapy for these patients ${ }^{55-57}$.

Rituximab is the de facto standard first-line treatment for $\mathrm{EBV}^{+}$post-transplant lymphoproliferative disorders despite not being approved for this indication owing to an acceptable risk to benefit ratio, with responses reported in the range of $44-66 \%$. Up to $50 \%$ of patients with a response, however, have disease relapse after rituximab therapy. Prockop et al. used off-the-shelf, allogeneic EBV-specific CTLs from HSCT donors without cancer to treat patients with R/R EBV-associated post-transplantation lymphoproliferative disorders. Complete or sustained partial remissions occurred in $68 \%$ of HSCT recipients and $54 \%$ of solid-organ transplant recipients, with a 1-year OS of $>80 \%$ among patients with complete or partial remissions or stable disease after cycle $1\left(\mathrm{REFS}^{56,58,59}\right)$. The use of autologous EBV-specific CTLs in patients with nasopharyngeal carcinoma or $\mathrm{EBV}^{+}$Hodgkin lymphoma is also associated with promising antitumour activity ${ }^{60,61}$. Other ongoing studies are seeking to determine whether EBV-associated antigens, such as those expressed by Hodgkin lymphoma and nasopharyngeal carcinoma cells, are amenable to EBV-specific CTL therapy (NCT03769467 and NCT01333046).

Human cytomegalovirus (CMV) antigen can be expressed in glioblastoma multiforme, which led to testing autologous CMV-directed CTLs as a consolidative treatment for patients with this malignancy. This approach was deemed safe and tolerable ${ }^{62}$.

Virus-specific T cells (VSTs) have also been used to treat severe and/or intractable viral infections after HSCT (from EBV, CMV or adenovirus), with a low incidence of de novo GVHD (2 of 50 patients) ${ }^{63}$. Similarly, VSTs targeting EBV (NCT01535885 and NCT02900976), CMV (NCT01535885 and NCT02210078), BK virus (NCT02479698), human poliovirus 2 (NCT02479698), human herpesvirus 6 and adenovirus (NCT01535885 and NCT03425526), as well as multi-virus VSTs (NCT02108522), are under investigation in trials involving adults, AYAs and children ${ }^{64}$. Off-the-shelf VSTs targeting BK virus have been used successfully to treat patients with progressive multifocal leukoencephalopathy and haemorrhagic cystitis, complications both seen after HSCT ${ }^{65,66}$. In the studies described, VST selection and/or expansion has been optimized to maximize viral cytotoxicity while minimizing alloreactivity, largely eliminating the risk of GVHD.

BiTEs. BiTEs can target a range of tumour-associated antigens and thus can be used to treat a variety of haematological and solid tumours ${ }^{67}$. The CD3-CD19-targeted BiTE blinatumomab has single-agent efficacy in children and adults with R/R B-ALL and minimal residual disease (MRD)-positive B-ALL, and a favourable toxicity profile. Treatment with blinatumomab has been associated with CRS and ICANS ${ }^{68}$.

ICIs. Immune checkpoints, including PD-1 and CTLA4, negatively control $\mathrm{T}$ cell-mediated immunity and have crucial roles in immune homeostasis and preventing autoimmunity ${ }^{69,70}$. Thus, immune checkpoints typically act as dependable mechanisms by which aberrant activation of the immune system is avoided, although they are frequently exploited by neoplastic cells to avoid antitumour $\mathrm{T}$ cell responses and thereby facilitate immune escape $\mathrm{e}^{71}$. 
The anti-CTLA4 antibody ipilimumab is an ICI approved by the FDA for the treatment of advanced-stage melanoma in patients aged $>12$ years $^{72-74}$. The spectrum of irAEs in younger patients seems similar to that described in adults, although toxicities can present earlier in children, after even a single dose ${ }^{73}$. In a phase I trial of ipilimumab in children and AYAs with solid tumours, OS outcomes were more favourable among those who had irAEs than in those who did not ${ }^{73}$. In an open-label, single-arm phase II trial, 12 adolescents with previously treated or untreated unresectable stage III-IV melanoma received ipilimumab (3 or $10 \mathrm{mg} / \mathrm{kg}$ every 3 weeks), with no treatment-related deaths reported ${ }^{74}$. The study was discontinued owing to slow accrual, highlighting the challenges facing trials involving children with rare diseases and the importance of inclusion in future trials of adolescents with cancer types that occur predominantly in adults ${ }^{74}$.

The anti-PD-1 antibody nivolumab is also tolerated by children, although a phase II trial revealed limited single-agent activity in patients with common paediatric malignancies $^{75}$. In this trial, the incidence of pleural or pericardial effusions was $15 \%$, mostly occurring during the first cycle and simultaneously ${ }^{75}$. Nivolumab, alone or combined with low-dose ipilimumab, has antitumour activity and is approved for use in adults and children with mismatch repair-deficient or microsatellite instability-high metastatic colorectal cancer that is resistant to chemotherapy ${ }^{76,77}$. Pembrolizumab, another anti-PD-1 antibody, is approved for the treatment of adults and children with R/R classic Hodgkin lymphoma and seems to be well tolerated in children; although potentially treatment-related deaths (pneumonitis with pleural effusion, and pulmonary oedema with sepsis) have been reported ${ }^{78}$. Reported AEs with pembrolizumab in adults include acute kidney injury (AKI), colitis, gastritis, adrenal insufficiency, hypertension, proteinuria, thrombocytopenia and hypokalaemia ${ }^{79,80}$.

The safety profiles of ICIs seem similar in children and adults, although close monitoring for earlier and more pronounced toxicities is warranted among younger children, particularly those aged $<12$ years ${ }^{73}$. Studies of combinations of ICIs with other immunotherapy agents to promote an immunogenic TME or directly provide a $\mathrm{T}$ cell infiltrate might lead to the identification of ideal combinations, although monitoring for toxicities will be important $^{81}$.

\section{Toxicity grading and management}

IEC therapy is associated with CRS, ICANS and other systemic organ dysfunctions, such as cardiotoxicity ${ }^{82}$, and treatment with ICIs can result in severe irAEs ${ }^{83,84}$. In 2019, the ASTCT developed a grading system for IEC toxicity, which adopted key elements from the previously published, widely used CARTOX guidelines ${ }^{2,3,85}$, and the American Society of Clinical Oncology (ASCO) has developed guidelines for the management of irAEs in adults receiving ICIs ${ }^{86}$. Herein, we provide important considerations for the diagnosis, grading and management of toxicities associated with immunotherapies in children and AYAs (TABLE 1).
CRS. CRS has specific symptoms that can develop when immune cells are activated and release large amounts of cytokines following the administration of immunotherapies, especially those involving $\mathrm{T}$ cells. The incidence of CRS is variable, and occurred in almost half of children and AYAs with R/R B-ALL receiving blinatumomab and $77 \%$ of those receiving tisagenlecleucel in the phase II ELIANA study ${ }^{87,88}$. CRS is typically diagnosed by the presence of: (1) fever (temperature $\geq 38^{\circ} \mathrm{C}$ ) that is not attributable to any other cause as a defining symptom; (2) hypotension; and/or (3) hypoxia ${ }^{3}$ (FIG. 1). The ASTCT guidelines for the diagnosis of CRS are applicable to adults and children alike; however, high vigilance for diagnosis might be especially important among children and AYAs.

Patients with fever and/or hypotension should be assessed for signs and/or symptoms of sepsis (for example, with cultures and/or imaging), and empirical antimicrobial coverage should be initiated. Hypotension in young patients is defined by age-specific physiologically normal ranges and/or in comparison with the individual's baseline values ${ }^{89}$. Prompt recognition of hypotension in young patients should be followed by intensive management. Patients with CRS are at risk of AKI, which can occur in $46 \%$ of patients after CAR T cell therapy, owing to direct inflammatory injury, fluid shifts, hypoperfusion and shock ${ }^{90,91}$.

Renal tissue damage is associated with adverse outcomes even without a decrease in glomerular filtration rate, and thus in this context serum creatinine is not a sensitive biomarker of renal function. Cystatin C could be a more reliable functional biomarker that is not affected by age, muscle mass or tubular secretion, although it is affected by the use of steroids ${ }^{92}$. An acute rise in the levels of filtration markers can reflect either a physiological response to an altered haemodynamic state (functional AKI, previously called prerenal azotaemia) or renal tissue damage (intrinsic AKI). Tubular injury biomarkers, such as neutrophil gelatinase-associated lipocalin and a combination of metalloproteinase inhibitor 2 and insulin-like growth factor-binding protein 7, might enable more precise AKI prediction ${ }^{93,94}$. In the absence of complications, the optimal timing to start renal replacement therapy remains largely unknown and poorly supported by quality evidence-based research; this uncertainty translates into wide variation in treatment patterns and practices. Renal replacement therapy might be considered when fluid overload is $>10-15 \%$ or to manage electrolyte imbalances refractory to maximal recommended therapy. Additionally, prospective studies should address the effect of haemoadsorption with cartridge columns in combination with continuous renal replacement therapy on serum cytokine levels and the efficacy of CAR T cell therapy ${ }^{95}$. Overall, early recognition and management of CRS might be associated with reduced incidence of AKI and functional recovery within 30 days $^{96}$. In addition to AKI, hyponatraemia (sodium serum levels $<130 \mathrm{mEq} / \mathrm{l}$ ), hypokalaemia (potassium serum levels $<2.0 \mathrm{mEq} / \mathrm{l}$ ) and hypophosphataemia (phosphorus serum levels $<2.5 \mathrm{mg} / \mathrm{dl}$ ) are not uncommon after CAR T cell therapy and might result from the release of cortisol, intravascular volume 
Table 1 | Toxicities associated with cancer immunotherapy in children and AYAs, $\mathbf{s}^{3,85,86,130,141,191,192}$

\begin{tabular}{|c|c|}
\hline $\begin{array}{l}\text { Immunotherapy } \\
\text { product }\end{array}$ & Acute toxicities (within $\mathbf{3 0}$ days of immunotherapy) \\
\hline \multicolumn{2}{|l|}{ IEC therapies } \\
\hline CAR T cells & $\begin{array}{l}\text { Autologous CAR T cells: CRS, ICANS, organ dysfunction } \\
\text { (not captured in CRS grading), infection, infusion reactions }\end{array}$ \\
\hline & $\begin{array}{l}\text { Allogeneic CAR T cells: CRS, ICANS, GVHD, infection, infusion } \\
\text { reactions }\end{array}$ \\
\hline
\end{tabular}
reactions

TILs

Infusion reactions including: capillary leak syndrome ${ }^{\mathrm{d}}$,

myalgia, nausea, fever, rigors

'On-target, off-tumour' toxicities including: autoimmune sequelae such as rash, uveitis or vitiligo in patients receiving TILs that recognize melanoma-associated antigens

Engineered TCR 'On-target, off-tumour’ toxicities including: leukoencephaloptherapy athy, coma and death, all reported in patients with melanoma receiving TCR-engineered T cells targeting MAGEA3

Cardiogenic shock, death, reported in patients with multiple myeloma or melanoma receiving TCR-engineered T cells targeting MAGEA3

Rash, uveitis and hearing impairment, all reported in patients with melanoma receiving TCR-engineered T cells targeting MART-1 or gp100

$\begin{array}{ll}\text { NK cells } & \begin{array}{l}\text { Infusion reactions, headache, fatigue, slurred speech, } \\ \text { thrombocytopenia, neutropenia, GVHD, pulmonary toxicitie }\end{array} \\ \text { VSTs and CTLs } & \begin{array}{l}\text { Infusion reactions, GVHD, pseudoprogression, pulmonary } \\ \text { toxicities }\end{array}\end{array}$

Other immunotherapies

BiTEs

CRS, ICANS, infections, infusion reactions, cytopenias, disseminated intravascular coagulation

$\mathrm{ICls}$

CRS, infusion reaction, pruritus, fatigue, rash, pseudoprogression

Neurological: neurotoxicity, encephalitis

Gl: decreased appetite, nausea, colitis, pancreatitis

Hepatic: hepatitis, transaminitis

Cardiac: myocarditis, syncope

Pulmonary: oedema, pneumonitis

Renal: acute kidney injury

Endocrinopathies: ACTH insufficiency, hypothyroidism or hyperthyroidism, hypophysitis

Rheumatological: arthralgia, arthritis, myositis, Sicca syndrome, other autoimmune phenomena (such as nephritis)

Haematological: haemolytic anaemia, immunological thrombocytopenia purpura, neutropenia

Management of acute toxicities

\section{Late toxicities ${ }^{\mathrm{a}}(>\mathbf{3 0}$ days after immunotherapy)}

Supportive care

Corticosteroids, tocilizumab

Additional

therapies to be considered: dasatinib, anakinra, cyclophosphamide, ATG, activation of 'safety switches'

Supportive care

Corticosteroids

\section{Supportive care}

Corticosteroids
Grade 3-4 cytopenias, B cell aplasia and/or hypogammaglobulinaemia ${ }^{b}$

Progressive multifocal leukoencephalopathy

Malignancy clonality

Reactivation of hepatitis $B$ and $C$

Theoretically, potential for insertional oncogenesis, secondary malignancies, replication-competent viral vectors, immunogenicity and presence of anti-mouse antibodies against CAR T cells ${ }^{c}$

Autoimmune sequelae

None reported

Supportive care

None reported

Corticosteroids

Supportive care

Corticosteroids

None reported

Serial imaging

to monito

pseudoprogression

Supportive care

B cell aplasia and

Corticosteroids, hypogammaglobulinaemia ${ }^{\mathrm{b}}$

tocilizumab

Supportive care

Endocrinopathies

Corticosteroids

Autoimmune sequelae

Serial imaging

to monitor pseudoprogression

Discontinuation of ICls if grade 4 toxicities occur

Additional therapies to be considered if resistance to steroids: infliximab ACTH, adrenocorticotropic hormone; ATG, anti-thymocyte globulin; AYAs, adolescents and young adults; BiTE, bispecific T cell engager; CAR, chimeric
antigen receptor; CRS, cytokine-release syndrome; CTL, cytotoxic lymphocyte; Gl, gastrointestinal; GVHD, graft-versus-host disease; ICANS, immune effector cell-associated neurotoxicity syndrome; ICl, immune-checkpoint inhibitor; IEC, immune effector cell; NK, natural killer; TCR, T cell receptor; TIL, tumour-infiltrating lymphocyte; VST, virus-specific T cell. a Management of late toxicities should follow available standard-of-care guidelines for specific complications. ${ }^{\circ}$ Observed with CD19-targeted therapy. ${ }^{~}$ The link between presence of these antibodies and efficacy and/or persistence of CAR T cells remains to be determined. ${ }^{\circ}$ When TILs are coadministered with $\mathrm{LL}-2$ 

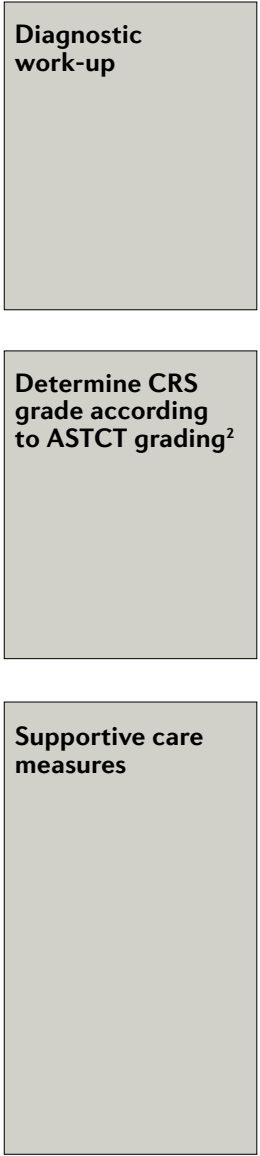

Anti-IEC therapies
As indicated

- Assess for infection:

(Blood culture, urine culture, chest radiography)

- Cardiac telemetry and pulse oximetry

- Echocardiography

- Other studies as indicated

$\downarrow$

\begin{tabular}{|c|c|c|c|}
\hline \multicolumn{4}{|c|}{ Other possible aetiologies of symptoms excluded and suggestive of CRS } \\
\hline $\begin{array}{l}\text { Grade } 1 \\
\text { Fever }^{\mathrm{a}}\end{array}$ & \begin{tabular}{l} 
Grade 2 \\
Fever $^{\mathrm{a}} \quad$ AND \\
Hypotension not requiring \\
vasopressors \\
\multicolumn{1}{c}{ AND/OR } \\
Hypoxia requiring low-flow \\
nasal cannula NC or blow \\
by $\mathrm{O}_{2}$
\end{tabular} & $\begin{array}{l}\text { Grade } 3 \\
\text { Fever }^{\mathrm{a}} \quad \text { AND } \\
\text { Hypotension requiring one } \\
\text { vasopressor } \pm \text { vasopressin }{ }^{\mathrm{b}} \\
\quad \text { AND/OR } \\
\text { Hypoxia requiring high-flow } \\
\text { nasal cannula or facemask or } \\
\text { non-rebreather mask or } \\
\text { Venturi mask }\end{array}$ & $\begin{array}{l}\text { Grade } 4 \\
\text { Fever }^{a} \quad \text { AND } \\
\text { Hypotension requiring } \\
\text { multiple vasopressors, not } \\
\text { including vasopressin }{ }^{\mathrm{b}} \\
\quad \text { AND/OR } \\
\text { Hypoxia requiring positive } \\
\text { airway pressure }\end{array}$ \\
\hline $\begin{array}{l}\text { - Antipyretics } \\
\text { - Cooling measures } \\
\text { - Antibiotics } \\
\text { - Maintenance Hydration } \\
\text { - Symptomatic management } \\
\text { of constitutional symptoms } \\
\text { - Initiate seizure prophylaxis } \\
\text { (if not ongoing already) }\end{array}$ & $\begin{array}{l}\text { - Supportive care measures } \\
\text { defined for grade } 1 \\
\text { - i.v. fluid bolus as needed } \\
\text { - Consider stress-dose } \\
\text { hydrocortisoned } \\
\text { - } \mathrm{O}_{2} \text { supplementation }\end{array}$ & $\begin{array}{l}\text { - Supportive care measures } \\
\text { defined for grade } 1 \\
\text { - Transfer to ICU } \\
\text { - i.v. fluid bolus as needed } \\
\text { - Consider stress-dose } \\
\text { hydrocortisone } \\
\text { - Vasopressors as needed } \\
\text { - } \mathrm{O}_{2} \text { supplementation }\end{array}$ & $\begin{array}{l}\text { - Supportive care measure } \\
\text { defined for grade } 1 \\
\text { - Transfer to ICU } \\
\text { - i.v. fluid bolus as needed } \\
\text { - Consider stress-dose } \\
\text { hydrocortisone } \\
\text { - Vasopressors as needed } \\
\text { - Positive-pressure } \\
\text { ventilation as needed }\end{array}$ \\
\hline & $\begin{array}{l}\text { Recurrent hypotension } \\
\text { requiring } \geq 2 \text { consecutive i.v. } \\
\text { fluid boluses and/or initiation } \\
\text { of } \mathrm{O}_{2} \text { supplementation }\end{array}$ & & \\
\hline
\end{tabular}

- Tocilizumab (12 mg/kg for patients weighing $<30 \mathrm{~kg}$ OR $8 \mathrm{mg} / \mathrm{kg}$ for those weighing $\geq 30 \mathrm{~kg}$ )

- Maximum of $800 \mathrm{mg} /$ dose

- Can be repeated every $8 \mathrm{~h}$ for up to 3 doses in a 24-h period or up to 4 doses over the entire CRS course

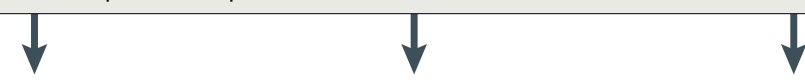

Reassess every $6 \mathrm{~h}$ or earlier if clinically indicated

Consider methylprednisolone or dexamethasone ${ }^{e}$ for:

- Persistent hypotension - Rapid progression of pulmonary infiltrates and/or

- Vasopressor use - Need for increasing respiratory support

- Persistent hypoxia - Concern for intubation
Consider additional therapies including activation of safety switches if:

- Grade 4 hypotension AND/OR

- Hypoxia refractory to treatment for $>24$ hours OR

- Patient is deteriorating rapidly depletion or IL-6-mediated increases in vasopressin secretion in the context of $\mathrm{CRS}^{97}$.

The use of normal saline solution might be associated with increases in hyperchloraemic metabolic acidosis, the occurrence of AKI and possibly mortality compared with balanced solutions ${ }^{98}$. Alternatively, albumin administration might be favourable in patients with
CRS, especially in those with CLS and hypoalbuminaemia. CLS has been described in patients with CRS and might be more common in patients with severe CRS; albumin administration might reduce the duration of treatment with vasopressors and decrease respiratory, cardiovascular and neurological organ failure scores ${ }^{99-101}$. In patients who are critically ill, albumin administration 
4 Fig. 1 | Grading and management of cytokine-release syndrome $e^{2,3}$. Cytokine-release syndrome (CRS) is a potentially life-threatening complication of immunotherapy, especially therapies involving direct activation of T cells. Patients receiving these therapies should be vigilantly monitored for this complication, incorporating consideration of age-appropriate vital signs to facilitate the early recognition and prompt management of CRS. ASTCT, American Society for Transplantation and Cellular Therapy; ICANS, immune effector cellassociated neurotoxicity syndrome; ICU, intensive care unit; IEC, immune effector cell; i.v., intravenous. In patients who have CRS and have received antipyretic or cytokine blockade therapy, fever is no longer required to subsequently grade CRS but rather, grading is driven by hypotension and/or hypoxia and is determined by the more severe event. ${ }^{b} H y p o t e n s i o n$ is defined by age-specific physiologically normal ranges and/or by comparison with the patient's baseline values; when baseline systolic blood pressures (SBPs) are unknown, hypotension can be determined as SBP $<60 \mathrm{mmHg}$ in term neonates ( $0-28$ days), SBP $<70 \mathrm{mmHg}$ in infants (1-12 months), $\mathrm{SBP}<70+$ (age in years $\times 2$ ) $\mathrm{mmHg}$ in children aged $1-10$ years, and SBP $<90 \mathrm{mmHg}$ in children aged $>10$ years. ${ }^{c} 10-20 \mathrm{ml} / \mathrm{kg}$ (maximum $1,000 \mathrm{ml}$ ) normal saline solution; repeat once as needed to maintain physiologically normal blood pressure above baseline or within age-defined range described above. ${ }^{\mathrm{d}}$ For hypotension, consider hydrocortisone $12.5-25 \mathrm{mg} / \mathrm{m}^{2}$ daily divided every $6 \mathrm{~h}$, if possible adrenal insufficiency. ${ }^{~}$ For grade 2 hypotension: methylprednisolone $1-2 \mathrm{mg} / \mathrm{kg}$ for one dose or dexamethasone $0.15-0.5 \mathrm{mg} / \mathrm{kg}$ per dose (maximum dose $10 \mathrm{mg}$ ) i.v. for one dose. For grade 2 hypoxia: one dose of either methylprednisolone $1-2 \mathrm{mg} / \mathrm{kg}$ or dexamethasone $0.5 \mathrm{mg} / \mathrm{kg}$ (maximum dose $10 \mathrm{mg}$ ) i.v. For grade 3 hypotension: if on one vasopressor, methylprednisolone $1-2 \mathrm{mg} / \mathrm{kg}$ daily divided every $6-12 \mathrm{~h}$ or dexamethasone $0.5 \mathrm{mg} / \mathrm{kg}$ per dose (maximum dose $10 \mathrm{mg}$ ) i.v. every $6 \mathrm{~h}$; if on two vasopressors, methylprednisolone $1-2 \mathrm{mg} / \mathrm{kg}$ daily divided every $6-12 \mathrm{~h}$ or dexamethasone $1 \mathrm{mg} / \mathrm{kg}$ per dose (maximum dose $20 \mathrm{mg}$ ) i.v. every $6 \mathrm{~h}$; if vasopressin and norepinephrine equivalent is $\geq 15 \mu \mathrm{g} / \mathrm{min}$, follow recommendations for grade 4 CRS. For grade 3 hypoxia: methylprednisolone $1-2 \mathrm{mg} / \mathrm{kg}$ daily divided every $6-12 \mathrm{~h}$ or dexamethasone $0.5 \mathrm{mg} / \mathrm{kg}$ per dose (maximum dose $10 \mathrm{mg}$ ) i.v. every $6 \mathrm{~h}$; if hypoxia does not improve within $24 \mathrm{~h}$, pulmonary infiltrates progress rapidly or fraction of inspired oxygen requirements increase sharply, methylprednisolone $1-2 \mathrm{mg} / \mathrm{kg}$ daily divided every $6-12 \mathrm{~h}$ or dexamethasone $1 \mathrm{mg} / \mathrm{kg}$ per dose (maximum dose $20 \mathrm{mg}$ ) i.v. every $6 \mathrm{~h}$. For grade 4 hypotension or hypoxia: methylprednisolone $30 \mathrm{mg} / \mathrm{kg}$ daily (maximum daily dose $1,000 \mathrm{mg}$ ) in divided doses i.v. over 3 days followed by rapid tapering as per clinical situation. For CRS grades $2-4$ : once CRS improves to grade $\leq 1$, taper and/or

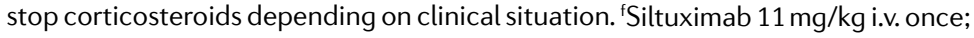
anakinra (children aged $\geq 2$ years and adolescents only) $1 \mathrm{mg} / \mathrm{kg}$ (maximum dose $100 \mathrm{mg}$ ) subcutaneously daily for 7 days; cyclophosphamide $1,500 \mathrm{mg} / \mathrm{m}^{2}$ i.v. once (with mesna $1,500 \mathrm{mg} / \mathrm{m}^{2}$ i.v. over $24 \mathrm{~h}$ for one dose); or anti-thymocyte globulin (rabbit) $1-2 \mathrm{mg} / \mathrm{kg}$ i.v. daily for 3 days. be associated with fever, and can lead to high energy expenditure and resultant acute respiratory failure ${ }^{89,102}$. The tidal volume of each breath and the peak inspiratory flow rate both increase with patient age. Conversely, extrathoracic dead space can be up to two to three times greater in children than in adults. Furthermore, the peripheral airway resistance in healthy children $<5$ years of age can be up to four times higher than that in adults. Inflammatory pathologies can further exacerbate this difference, with a reduction in the diameter of the airway of up to $50 \%$ and a 16 -fold increase in airway resistance ${ }^{102,103}$.

Low-flow supplemental oxygen via a nasal cannula (typically $2-41 / \mathrm{min}$ in children; oxygen flow rates via a high-flow nasal cannula (HFNC) of $>61 /$ min by ASTCT consensus criteria) can improve hypoxaemia in children, although the precise fraction of inspired oxygen at each flow rate is difficult to determine because of the dilution of oxygen with entrained air and variability in the degree of dilution with variations in tidal volume, minute volume, respiratory rate, inspiratory and expiratory times and flows, anatomical dead space and the effect of an open or closed mouth ${ }^{104}$. Therefore, low-flow supplemental oxygen might not provide the same level of respiratory support in a 10-year-old child as it does in a 1-year-old; this difference should be considered when assessing a child with CRS. HFNC can benefit patients with respiratory symptoms from CRS by reducing energy expenditure, increasing carbon dioxide washout of nasopharyngeal dead space, facilitating mucociliary function with clearance of secretions and preventing atelectasis $^{102,105}$. HFNC flow rates of $1.5-2.01 / \mathrm{kg} / \mathrm{min}$ have been associated with a reduction in breathing effort, unloading of accessory muscle use and generation of positive pressure with a mean pharyngeal pressure of $\geq 4 \mathrm{cmH}_{2} \mathrm{O}$ in children ${ }^{106,107}$.

In children with grade $\geq 3$ CRS in whom low-flow oxygen and HFNC are insufficient, non-invasive ventilation with continuous or bilevel positive airway pressure might be a viable option. If indicated, non-invasive positive pressure ventilation should be administered in the paediatric intensive care unit and should not delay intubation. When triggered by patient inspiration, non-invasive ventilation can augment tidal volumes and thereby a patient's minute ventilation. Non-invasive ventilation can deliver higher pressures to overcome airway resistance, enhance ventilation and prevent atelectasis more effectively than HFNC; however, it requires a tight-fitting mask that can be uncomfortable. In addition, the forced air entering the upper airway with non-invasive ventilation can cause distension of the stomach placing susceptible patients at risk of emesis and aspiration ${ }^{108}$. Both HFNC and non-invasive ventilation can be sufficient to alleviate the respiratory symptoms of CRS, although failure rates of $26.9 \%$ and $28 \%$, respectively, have been reported ${ }^{108,109}$. Therefore, clinicians must rigorously monitor paediatric patients with CRS to observe the evolution of their respiratory status.

In general, first-line therapy for diagnosed CRS involves administration of IL- 6 blockers, such as the anti-IL-6R antibody tocilizumab, which can be considered in patients with grade 1-2 CRS and should be administered in those with grade 3-4 CRS (FIG. 1). 
In patients with grade 2-4 CRS, stress-dose hydrocortisone should be considered if hypotension from adrenal insufficiency is a possible cause of symptoms. Corticosteroids (methylprednisolone or dexamethasone) can be administered for persistent hypotension, vasopressor need, hypoxia and/or ICANS. In patients with grade 4 CRS, higher dosing of methylprednisolone should be considered. Corticosteroids should be tapered or discontinued once CRS improves to grade $\leq 1$. In the rare patients in whom these interventions do not improve outcomes, additional therapies to consider include activation of 'safety switches' to directly curtail IEC activity. These approaches include dasatinib as a pharmacological on/off switch, the recombinant IL-1R antagonist anakinra, cyclophosphamide and anti-thymocyte globulin ${ }^{2,3,14,85,110,111}$.

Early initiation of therapy with anti-IL-6 antibodies and/or corticosteroids (within 24 hours) has been associated with reduced severity of CRS without affecting CAR T cell efficacy ${ }^{112,113}$. Although individual institutional algorithms, FDA labels and research protocols vary regarding specific management strategies, prompt recognition and mitigation of severe CRS remains a common goal. Trials are underway to explore the use of the JAK1 selective inhibitor itacitinib to prevent CRS induced by tisagenlecleucel or axicabtagene ciloleucel (NCT04071366), and anakinra for the prevention of CRS and neurotoxicity in patients with B cell lymphomas receiving axicabtagene ciloleucel (NCT04359784). Prospective studies might provide information on optimal prophylaxis and mitigation strategies across a variety of CAR $T$ cell products and among various disease indications.

ICANS. ICANS is a pathological process involving the CNS following any immunotherapy that activates or engages endogenous or infused $\mathrm{T}$ cells and/or other IECs $^{3}$. ICANS can be progressive and includes a wide range of symptoms, such as headache, pain, meningismus, short-term memory loss, altered mental status, impaired speech (dysarthria and/or aphasia), impaired cognitive skills, motor weakness, movement disorders (tremor, myoclonus and/or facial automatisms), seizures, encephalopathy and cerebral oedema ${ }^{3,85,114}$. Following tisagenlecleucel treatment, $40 \%$ and $39 \%$ of patients with ALL and non-Hodgkin lymphoma (NHL), respectively, had neurological toxicities within the first 8 weeks, with a median duration of symptoms of 6 days and 14 days, respectively ${ }^{87,115}$. The incidence of reported neurological toxicities (64\%) was higher and the median duration of neurological toxicity was longer (17 days) in patients with B cell malignancies receiving axicabtagene ciloleucel ${ }^{116}$. In all groups, the median time to onset of symptoms was 4-6 days ${ }^{87,115,116}$.

The Immune Effector Cell-Associated Encephalopathy (ICE) score is an encephalopathy assessment tool used for grading of ICANS in patients aged $>12$ years, with the highest score (ten) suggesting no cognitive impairment ${ }^{3}$. The ASTCT Consensus Grading adopted our recommendation ${ }^{3}$ of using the Cornell Assessment of Paediatric Delirium (CAPD) for encephalopathy screening in children and AYAs for ICANS assessment ${ }^{3}$.
CAPD is routinely used for delirium screening in patients aged $\leq 12$ years and in those aged $>12$ years in whom this tool is developmentally appropriate ${ }^{117}$. A CAPD score of nine or more suggests delirium. A rising CAPD score from a patient's baseline is also relevant; for example, a patient with a CAPD score of four who later has a score of seven might be at increased risk of delirium and warrants more frequent monitoring. During the expected high-risk period for ICANS, CAPD and ICE scores should be evaluated at least twice daily in patients receiving IEC therapies, with an increased frequency of monitoring if the patient experiences any neurological event, such as decreased level of consciousness, rising CAPD score above the patient's baseline, seizures or focal neurological findings.

Consideration of the child's chronological as well as developmental age can ensure that the appropriate developmental screening tool is used initially. ICANS grade is determined by the most severe event (ICE or CAPD score, level of consciousness, seizure occurrence, motor findings or raised intracranial pressure and/or cerebral oedema) not attributable to any other cause ${ }^{3}$. Hence, the diagnostic work-up can include neuroimaging, neurology consultation and/or electroencephalography, and diagnostic lumbar puncture, if other causes of encephalopathy are suspected or if ICANS persists. Diffuse background slowing on electroencephalography was reported in $83.3 \%$ of paediatric and AYA patients with seizures due to grade $\geq 3$ ICANS $^{118}$. Similar findings of background showing abnormalities on electroencephalography have been reported in up to $76 \%$ of adults receiving CAR T cells possibly indicating clinical or subclinical seizure ${ }^{119,120}$. In these patients, neuroimaging (usually brain CT and/or MRI) typically produced physiologically normal results, although $43 \%$ of patients underwent acute MRI scans, that revealed severe neurotoxicity in $\sim 30 \%$, and thus a clear imaging pattern has not been described ${ }^{119,120}$. The spectrum of imaging findings ranges from the most severe and often fatal diffuse cerebral oedema pattern to reversible, oftentimes symmetrical periventricular white matter T2 hyperintensity, with or without involvement of the deep grey matter ${ }^{19,120}$. Intracranial haemorrhages, infarcts, leptomeningeal enhancement, posterior reversible encephalopathy syndrome and excitotoxicity-related injury patterns affecting the mesial temporal lobes and splenium have also been reported ${ }^{119,120}$.

Transfer to a paediatric intensive care unit is indicated in patients with grade $\geq 3$ ICANS, with progressive ICANS or ICANS that is non-responsive to tocilizumab and steroids. Aspiration precautions, avoidance of medications that cause CNS depression, blood pressure control with the goal of maintaining a mean arterial pressure within $20-25 \mathrm{mmHg}$ of baseline, control of raised intracranial hypertension, correction of uraemia and coagulopathy (if present) and initiation and/or continuation of prophylactic anti-seizure medication is recommended in patients with ICANS and should be initiated as early as possible upon transfer to the intensive care unit. Nonpharmacological measures, such as agitation with careful monitoring, or low doses of haloperidol, precedex, olanzapine or respiridol, can be used. 
Specific management includes the addition of tocilizumab for all grades of ICANS if concurrent with CRS. If no response to tocilizumab occurs or if ICANS is isolated, dexamethasone or methylprednisolone can be administered and dose escalated as needed. For focal oedema or grade 4 ICANS, methylprednisolone is recommended. Continuation of corticosteroids is recommended until ICANS is reduced to grade $\leq 1$. However, if grade 4 ICANS is refractory for $>24$ hours, additional therapies, such as those recommended for CRS, and activation of safety switches should be considered (FIG. 2).

Secondary CAR T cell-related HLH. Secondary CAR $\mathrm{T}$ cell-related haemophagocytic lymphohistiocytosis $(\mathrm{HLH})$ is a rare and diagnostically challenging complication of IEC therapy. A diagnosis of secondary HLH diagnosis should be considered in patients with a maximum serum concentration of ferritin of $>10,000 \mathrm{ng} / \mathrm{ml}$ during the high-risk period for CRS and who develop any two of the following organ toxicities after IEC therapy: grade $\geq 3$ liver, kidney or lung toxicities (per CTCAEv5.0) and/or haemophagocytosis determined by morphology assessment and/or CD68-positivity in the bone marrow or other organs on immunohistochemistry ${ }^{2,85}$. Analysis of the serum levels of fasting triglycerides and soluble IL-2R should be considered in patients with suspected secondary HLH.

Secondary HLH that develops in children receiving IECs is generally responsive to cytokine blockade therapies (tocilizumab and/or corticosteroids). Patients with suspected CAR T cell-related HLH without grade $\geq 3$ organ toxicities as mentioned above should be closely monitored, with appropriate supportive care. We recommend monitoring serum levels of ferritin, lactate dehydrogenase, fibrinogen, transaminases, bilirubin and creatinine while patients are receiving cytokine blockade therapies. If no improvement occurs after 48 hours, continue treatment or consider anakinra. Successful treatment of 12 children with rheumatic disease-related macrophage-activation syndrome with anakinra and various combinations of conventional therapy (including corticosteroids, cyclosporine A, intravenous immunoglobulin (IVIG) and etoposide and etanercept) has been described $^{121}$. In the rare event of treatment-refractory CAR T cell-related HLH, etoposide $\left(150 \mathrm{mg} / \mathrm{m}^{2}\right.$ intravenously twice weekly during weeks 1 and 2 , then once weekly) can be used. If concurrent ICANS occurs, the use of intrathecal cytarabine $(30 \mathrm{mg}$ in children $1-2$ years of age, $50 \mathrm{mg}$ in those $2-3$ years of age, and $70 \mathrm{mg}$ in those $\geq 3$ years of age) with or without intrathecal hydrocortisone (15 mg, $25 \mathrm{mg}$ and $50 \mathrm{mg}$, respectively) can also be considered ${ }^{85,122}$.

Allogeneic IEC-associated acute GVHD. Compared with autologous IEC products, the use of allogeneic IEC products might reduce impediments to successful leukapheresis and manufacturing times. Yet, these products might also be associated with potentially lifethreatening $\mathrm{GVHD}^{123}$. We outline staging, grading and suggested management approaches for IEC-associated acute GVHD, with specific paediatric considerations
(Supplementary Table 1). Treatment of allogeneic IECassociated GVHD could be product-dependent and include the use of topical or systemic steroids along with consideration of activation of safety switches as needed. Of note, body surface area (BSA) based on age and stool output quantification based on the patient's body weight (milligrams per kilogram) provide information on GVHD severity in children and AYAs ${ }^{124-126}$.

Severe irAEs. The TME includes regulatory T cells, myeloid-derived suppressor cells (MDSCs), $\gamma \delta \mathrm{T}$ cells, tumour-associated macrophages and other cell types expressing inhibitory immune checkpoints. Consequently, ICIs can disrupt TME homeostasis, often with beneficial antitumour effects, but can also promote autoimmune $\mathrm{AEs}^{127,128}$. Anti-CTLA4 antibodies have generally been associated with more severe irAEs than anti-PD-1 antibodies. Common irAEs include rash, pruritus, fatigue, nausea, diarrhoea, anorexia, hypothyroidism, hyperthyroidism and pneumonitis ${ }^{129-131}$. Diarrhoea occurs in $\sim 50 \%$ of adults receiving anti-CTLA4 ICIs. PD-1 and PD-L1 are expressed on cardiomyocytes, and thus anti-PD-1 antibodies can cause chest pain, shortness of breath, pulmonary oedema, syncope, cardiogenic shock or death ${ }^{86,130}$. In a trial involving a small cohort of paediatric patients receiving anti-PD- 1 treatment following CAR T cell infusion, irAEs included acute pancreatitis, hypothyroidism, arthralgia, urticaria and grade 3-4 cytopenias, with no grade 5 toxicities or GVHD observed $^{132}$. Cerebral oedema, infusion reactions, rash and diarrhoea have also been reported in children receiving ICIs ${ }^{133-138}$.

ASCO clinical practice guidelines provide important information that can be used for general diagnosis and management of irAEs in children and AYAs receiving ICIs $^{86}$. Indeed, close monitoring is warranted among young children particularly those aged $<12$ years because earlier and more pronounced toxicities might be observed in this population ${ }^{73}$. Broadly, the management of irAEs relies on the use of steroids as first-line therapy when holding administration of ICIs is insufficient ${ }^{139,140}$ (TABLE 2). Generally, ICIs can be continued with close monitoring in patients with grade 1 toxicities, with the exception of some neurological, haematological and cardiac toxicities. ICIs are usually held in patients with grade 2 irAEs until resolution; corticosteroids can be administered. High-dose corticosteroids should be initiated and ICI therapy held in the event of grade 3 irAEs. Corticosteroids should be tapered over the course of at least 4-6 weeks. If symptoms do not improve within 48-72 hours of high-dose corticosteroids, the anti-TNF antibody infliximab can be considered. When symptoms and/or laboratory values show reversion to grade $\leq 1$ irAEs, rechallenging with ICIs is an option, although caution is needed among patients with early onset irAEs. Dose adjustments are not recommended. Grade 4 toxicities usually warrant permanent discontinuation of ICIs, with the exception of endocrinopathies, which can be managed with hormone replacement ${ }^{86,141}$.

The ASCO guidelines ${ }^{86}$ are useful but were developed for adults. Detailed anticipatory guidance to patients and caregivers, with attention to age-appropriate and 


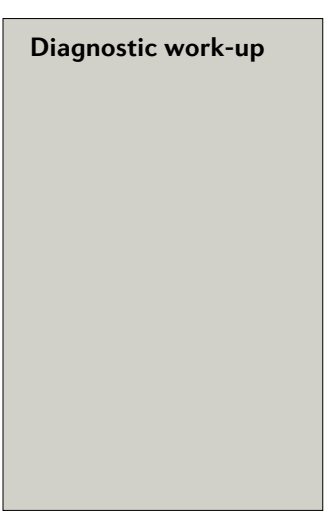

Determine ICANS grade according to ASTCT grading $^{2}$

Supportive care measures

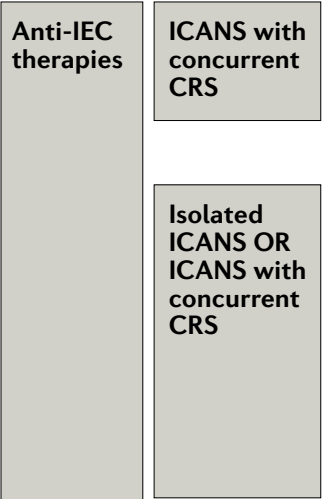

\section{As indicated:}

- MRI of the brain with and without contrast

- CT scan of brain without contrast if MRI is not feasible

- Consider repeat neuroimaging (CT or MRI) if persistent encephalopathy OR until resolution of cerebral oedema OR if clinically indicated

- MRI spine if focal deficits noted

- Neurology consultation

- Electroencephalography

- Lumbar puncture

- Assessment of ICE ${ }^{a}$ score and/or CAPD ${ }^{a}$ every $6 \mathrm{~h}$ or more frequently if indicated; increase monitoring frequency if CAPD $<9$ but rising from baseline

- Other studies as indicated

\begin{tabular}{|c|c|c|c|}
\hline \multicolumn{4}{|c|}{ Other possible aetiologies of symptoms excluded and suggestive of ICANS } \\
\hline$\perp$ & 1 & 1 & \\
\hline $\begin{array}{l}\text { Grade } 1 \\
\text { - Encephalopathy and/or } \\
\text { depressed level of } \\
\text { consciousness }{ }^{b} \text { (awakens } \\
\text { spontaneously) } \\
\text { - ICE } \text { Icore } 7-9^{\text {OR }} \\
\text { - CAPD score 1-8 }\end{array}$ & $\begin{array}{l}\text { Grade } 2 \\
\text { - Encephalopathy } \\
\text { and/or depressed level } \\
\text { of consciousness } \\
\text { (awakens to voice) } \\
\text { - ICE score 3-6 } \\
\text { OR } \\
\text { - CAPD }{ }^{\mathrm{b}} \text { score 1-8 }\end{array}$ & $\begin{array}{l}\text { Grade } 3 \\
\text { - Encephalopathy and/or } \\
\text { depressed level of } \\
\text { consciousness }^{\mathrm{b}} \text { (awakens } \\
\text { to tactile stimulus) } \\
\text { - ICE } \text { Icore } 0-2^{\text {OR }} \\
\text { OR } \\
\text { - CAPD score } \geq 9 \\
\text { OR } \\
\text { unable to perform CAPD } \\
\text { - Seizure } \\
\text { - Focal cerebral oedema }\end{array}$ & $\begin{array}{l}\text { Grade } 4 \\
\text { - Encephalopathy and/or depressed } \\
\text { level of consciousness } \\
\text { (unarousable or requires } \\
\text { vigorous tactile stimulus) } \\
\text { - ICE a score } 0 \text { OR obtunded } \\
\text { - Seizure } \\
\text { - Focal motor weakness } \\
\text { - Raised intracranial pressure } \\
\text { and/or diffuse abnormalities on } \\
\text { electroencephalography }\end{array}$ \\
\hline \multicolumn{2}{|c|}{$\begin{array}{l}\text { - Initiate aspiration precautions } \\
\text { - Ensure airway protection } \\
\text { - i.v. fluid as needed } \\
\text { - Convert all oral medications and or nutrition to i.v. } \\
\text { - Avoid mewing is impaired } \\
\text { - Non-pharmacolons that cause CNS depression } \\
\text { for agitation }\end{array}$} & \multicolumn{2}{|c|}{$\begin{array}{l}\text { - If no seizures on electroencephalography, continue } \\
\text { prophylactic levetiracetam } \\
\text { - Control hypertension } \\
\text { - Management for seizure and cerebral oedema } \\
\text { as per institutional guidelines } \\
\text { - Correction of uraemia } \\
\text { - Correction of coagulopathy } \\
\text { - Other care as indicated }\end{array}$} \\
\hline \multicolumn{4}{|c|}{$\begin{array}{l}\text { Tocilizumab }(12 \mathrm{mg} / \mathrm{kg} \text { for patients weighing }<30 \mathrm{~kg} \text { OR } 8 \mathrm{mg} / \mathrm{kg} \text { for those weighing } \geq 30 \mathrm{~kg} \text { ) } \\
\text { Maximum of } 800 \mathrm{mg} / \mathrm{dose} \\
\text { Can be repeated every } 8 \mathrm{~h} \text { for up to } 3 \text { doses in a } 24 \text {-h period or up to } 4 \text { doses over the entire CRS course }\end{array}$} \\
\hline \multicolumn{4}{|c|}{$\begin{array}{l}\text { - If the patient has isolated ICANS }>24 \mathrm{~h} \text { OR no response to tocilizumab for ICANS with concurrent CRS >24 } \mathrm{h} \\
\text { - Start dexamethasone } \mathrm{f} \text { i.v. }(1 \mathrm{mg} / \mathrm{kg} \text { per dose) } \\
\text { Maximum dose of } 20 \mathrm{mg} \text { every } 6 \mathrm{~h} \text { OR } \\
\text { - Methylprednisolone } \mathrm{i} \text { i.v. ( }(1-2 \mathrm{mg} / \mathrm{kg} \text { daily) divided every } 6-12 \mathrm{~h} \\
\text { - For focal oedema OR grade } 4 \text { ICANS: methylprednisolone } 30 \mathrm{mg} / \mathrm{kg} \text { daily (maximum dose of } 1,000 \mathrm{mg} \text { ) } \\
\text { - Reassess clinical status every } 6 \mathrm{~h} \text { or earlier if clinically indicated }\end{array}$} \\
\hline \\
\hline & & & $\begin{array}{l}\text { Consider additional therapies }{ }^{9} \\
\text { including activation of safety } \\
\text { switches if applicable if: } \\
\text { - Grade } 4 \text { ICANS present and } \\
\text { refractory for }>24 \mathrm{~h} \\
\text { OR } \\
\text { - Patient is deteriorating rapidly }\end{array}$ \\
\hline
\end{tabular}

weight-based considerations, could be important in the monitoring of children and AYAs receiving ICIs. The severity grading for dermatoses is based on the estimated BSA that is affected ${ }^{86}$. While the 'rule of nines' was designed to estimate BSA in adults, it might be less accurate in young children owing to their proportionally larger head and smaller mass in the legs and thighs ${ }^{142}$.
A 'rule of nines for children' assigns $18 \%$ BSA to the head while each leg is $13.5 \%$; the remaining body parts retain the same BSA percentages used in adults, with the anterior and posterior trunk each comprising 18\% BSA, each individual upper extremity comprising $9 \%$ BSA and the perineum $1 \% \mathrm{BSA}^{142}$. Similarly, gastrointestinal toxicities might be best graded in patients aged 
4 Fig. 2 | Grading and management of immune effector cell-associated neurotoxicity syndrome ${ }^{2,3,86}$. Immune effector cell-associated neurotoxicity syndrome (ICANS) is a potentially life-threatening complication of immunotherapy, especially that involving direct activation of T cells. Patients receiving these immunotherapies should be vigilantly monitored for ICANS, incorporating considerations of age-appropriate vital signs and use of paediatric delirium scores to facilitate the early recognition and prompt management of ICANS. ASTCT, American Society for Transplantation and Cellular Therapy; CAPD, Cornell Assessment of Paediatric Delirium; CNS, central nervous system; ICE, Immune Effector Cell-Associated Encephalopathy; IEC, immune effector cell; i.v., intravenous.

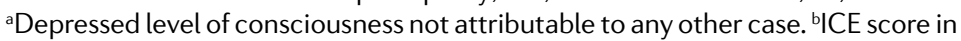
patients aged $>12$ years; CAPD in patients aged $\leq 12$ years and/or in those aged $>12$ years in whom this scoring system is developmentally appropriate. ${ }^{c}$ Any clinical seizure (focal or generalized) that resolves rapidly ( $<5$ minutes) or non-convulsive seizures on electroencephalography that resolve with intervention. 'Life-threatening prolonged seizure ( $\geq 5$ minutes) or repetitive clinical or electrical seizures without return to baseline in between. ${ }^{e}$ Control blood pressure with the goal of maintaining mean arterial pressure (MAP) within 20-25 mmHg of baseline MAP. ${ }^{f}$ Grade 1 : dexamethasone $0.5 \mathrm{mg} / \mathrm{kg}$ per dose (maximum dose $10 \mathrm{mg}$ ) i.v. for one dose (or methylprednisolone equivalent) and reassess in $6 \mathrm{~h}$ or earlier if clinically indicated. Grade 2: dexamethasone $0.5 \mathrm{mg} / \mathrm{kg}$ per dose (maximum dose $10 \mathrm{mg}$ ) i.v. every $12 \mathrm{~h}$ (or methylprednisolone equivalent). Grade 3 encephalopathy: dexamethasone $0.5 \mathrm{mg} / \mathrm{kg}$ per dose (maximum dose $10 \mathrm{mg}$ ) i.v. every $6 \mathrm{~h}$ (or methylprednisolone equivalent); if persistent for $>24 \mathrm{~h}$, increase dexamethasone to $1 \mathrm{mg} / \mathrm{kg}$ per dose (maximum dose $20 \mathrm{mg}$ ) i.v. every $6 \mathrm{~h}$ (or methylprednisolone equivalent). Grade 3 seizure: dexamethasone $1 \mathrm{mg} / \mathrm{kg}$ per dose (maximum dose $20 \mathrm{mg}$ ) i.v. every $6 \mathrm{~h}$ (or methylprednisolone equivalent). Grade 3 focal oedema in brain not including brainstem or thalamus: methylprednisolone $30 \mathrm{mg} / \mathrm{kg}$ (maximum dose $1,000 \mathrm{mg}$ ) in divided doses i.v. for 1 day; assess daily and continue or taper depending on clinical situation. Grade 3 focal oedema in brainstem or thalamus, or grade 4 ICANS: methylprednisolone $30 \mathrm{mg} / \mathrm{kg}$ daily (maximum daily dose 1,000 mg) in divided doses i.v. for 3 days followed by tapering depending on clinical situation. Grade 4 ICANS refractory or rapidly deteriorating: consider additional therapies ${ }^{9}$. For grades $2-3$, once ICANS improves to grade $\leq 1$, taper and/or stop corticosteroids depending on clinical situation. For all grades if concurrent CRS, add tocilizumab. ${ }^{9}$ Siltuximab $11 \mathrm{mg} / \mathrm{kg}$ i.v. once; anakinra (children aged $\geq 2$ years and adolescents only) $1 \mathrm{mg} / \mathrm{kg}$ (maximum dose $100 \mathrm{mg}$ ) subcutaneously daily for 7 days; cyclophosphamide $1,500 \mathrm{mg} / \mathrm{m}^{2}$ i.v. once (with mesna); or anti-thymocyte globulin (rabbit) $1-2 \mathrm{mg} / \mathrm{kg}$ i.v. daily for 3 days.

$<18$ years following the same approach as for GVHD staging (where severity is determined by volume of stool in millilitres per kilogram) ) $^{124-126}$ (Supplementary Table 1). Hypophysitis, a rare inflammatory disease of the pituitary gland, can present with non-specific symptoms including headache, mild fatigue, loss of libido and mood changes, which can be difficult to recognize in children. Careful age-appropriate and standardized symptom assessments, including screening for sexual development and health, might be important ${ }^{143}$. Endocrine complications can be reversible with hormone replacement therapy. The incidence of thyroid storm and myxoedema coma, while both rare in the general paediatric population, should be considered in the differential for children receiving ICIs ${ }^{84}$. Moreover, new onset of diabetes-related complications, such as diabetic ketoacidosis and hyperosmolar hyperglycaemia, can also be the first sign of irAEs ${ }^{144,145}$. Serial monitoring of the serum levels of corticotropin, thyrotropin, luteinizing hormone and follicle-stimulating hormone might be indicated in children receiving ICIs, possibly at baseline, 2 weeks after initiation of ICIs and then every $4-6$ weeks. Deviation from age-appropriate physiologically normal values could indicate the need for radiographic imaging, hormone replacement, administration of steroids and/or beta blockers, paediatric endocrinology evaluation and/or inpatient admission for more intensive clinical assessment $^{128}$. Immune-related pneumonitis can be serious and potentially fatal but often presents with non-specific features, including dyspnoea, chest discomfort, cough and/or, less commonly, fever ${ }^{146}$. Clinical manifestations can be quite difficult to distinguish from disease-related discomfort or other treatment-related complications, such as infection or anaemia, and/or can mimic asthma or allergic bronchopulmonary aspergillosis.

CT scans, particularly with high-resolution CT, can be helpful to detect radiographic patterns suggestive of cryptogenic organizing pneumonia, non-specific interstitial pneumonia, hypersensitivity pneumonitis and bronchiolitis (such as ground-glass opacities, consolidations, bronchiectasis, interlobular septal thickening and pleural effusions) ${ }^{147}$. Organizing pneumonia can appear as pulmonary nodules, thoracic (including hilar and mediastinal) adenopathy or granulomatosis in the setting of autoimmune pulmonary toxicity, which can be confused with new or worsening metastatic disease. The 'reversed halo' sign, which indicates central alveolar septal inflammation and cellular debris surrounded by granulomatous tissue within distal airways, can also be observed in patients with pulmonary irAEs. This sign appears as a central ground-glass opacity surrounded by a more dense region of consolidation, which is distinct from the halo sign associated with pulmonary haemorrhage typically seen in angioinvasive aspergillosis ${ }^{128,148}$. As discussed, attention to age-appropriate and weightbased clinically normal ranges for respiratory status in children can ensure prompt recognition of immune-related pneumonitis. Among patients who develop renal toxicities, paediatric grading should be based on age-appropriate Kidney Disease: Improving Global Outcomes Work Group (KDIGO) consensus criteria to define $\mathrm{AKI}^{149}$. Patients might present with sterile pyuria or subnephrotic-range proteinuria, but neither finding is sufficiently sensitive or specific to confirm or rule out ICI-related AKI. When present, eosinophilia can be helpful as a sign that confirms that AKI is ICI-mediated ${ }^{150}$.

\section{Pseudoprogression}

Pseudoprogression is a distinct response pattern best defined as radiological tumour progression from baseline that is not confirmed as progression on subsequent radiological assessment. Pseudoprogression has been described following administration of cancer immunotherapies, including IEC and ICIs, as a consequence of treatment-activated immune-cell infiltration into the $\mathrm{TME}^{151,152}$. Current radiographic response assessment criteria, such as Response Evaluation Criteria in Solid Tumors (RECIST) version 1.1, have been adapted for assessment of response to immunotherapies, resulting in the irRECIST, irRC or iRECIST criteria ${ }^{153-157}$. These methods are based on serial imaging to monitor disease progression, with the introduction of an additional follow-up scan to confirm or refute 'unconfirmed' tumour progression after an initial increase in lesion size $^{154,156}$. Differentiation of pseudoprogression from disease progression is clinically important to avoid continuation of ineffective treatment. Clinical diligence is imperative as the average time to response in patients with pseudoprogression is 6 months in children and 
Table 2 | Key considerations for the management of irAEs in children and AYAs receiving ICls $^{86,143,149,193}$

\begin{tabular}{|c|c|c|c|}
\hline $\begin{array}{l}\text { Toxicity } \\
\text { grade }\end{array}$ & Paediatric considerations & Management guidelines & $\begin{array}{l}\text { Future administration } \\
\text { of } \mathrm{ICls}\end{array}$ \\
\hline \multirow[t]{2}{*}{ Grade 1} & \multirow{2}{*}{$\begin{array}{l}\text { Use age-appropriate ranges for } \\
\text { vital signs }\end{array}$} & Continue $\mathrm{ICls}^{\mathrm{a}}$ & \multirow{3}{*}{$\begin{array}{l}\text { Carefully consider } \\
\text { rechallenging with } I C l s \\
\text { when irAE reverts to } \\
\text { grade } 1^{\text {b }}\end{array}$} \\
\hline & & Close monitoring for progression of toxicity & \\
\hline \multirow[t]{3}{*}{ Grade 2} & $\begin{array}{l}\text { Use Lund-Browder chart for } \\
\text { estimation of body surface area }\end{array}$ & Consider holding ICls until toxicities & \\
\hline & $\begin{array}{l}\text { Kidney injury reported according } \\
\text { to KDIGO quidelines: urine }\end{array}$ & $\begin{array}{l}\text { are resolved } \\
\text { Close monitoring for progression of toxicity }\end{array}$ & \multirow[t]{6}{*}{$\begin{array}{l}\text { Dose adjustment not } \\
\text { recommended }\end{array}$} \\
\hline & $\begin{array}{l}\text { output in millilitres per kilogram } \\
\text { per hour and change in creatinine } \\
\text { from baseline measurement }\end{array}$ & $\begin{array}{l}\text { Consider corticosteroids at a daily initial } \\
\text { dose of } 0.5-1 \mathrm{mg} / \mathrm{kg} \text { of prednisone or } \\
\text { prednisone equivalent }\end{array}$ & \\
\hline \multirow[t]{4}{*}{ Grade 3} & \multirow{2}{*}{$\begin{array}{l}\text { Stool volume to be measured in } \\
\text { millilitres per kilogram }\end{array}$} & Hold ICls until resolution of symptoms & \\
\hline & & Close monitoring for progression of toxicity & \\
\hline & $\begin{array}{l}\text { Use of age-appropriate reference } \\
\text { ranges for laboratory tests } \\
\text { (including thyroid hormones) }\end{array}$ & $\begin{array}{l}\text { High-dose corticosteroids: prednisone or } \\
\text { prednisolone } 1-2 \mathrm{mg} / \mathrm{kg} \text { daily }\end{array}$ & \\
\hline & \multirow{3}{*}{$\begin{array}{l}\text { Careful assessment for } \\
\text { non-specific symptoms related to } \\
\text { mood changes and libido, which } \\
\text { might be difficult to recognize in } \\
\text { children }\end{array}$} & $\begin{array}{l}\text { Consider infliximab if no resolution of } \\
\text { symptoms within } 48-72 \text { h of high-dose } \\
\text { corticosteroids }\end{array}$ & \\
\hline \multirow[t]{2}{*}{ Grade 4} & & Discontinue $\mathrm{ICls}$ & \multirow{2}{*}{$\begin{array}{l}\text { Permanent } \\
\text { discontinuation }^{c}\end{array}$} \\
\hline & & Management as recommended for grade 3 & \\
\hline
\end{tabular}

AYAs, adolescents and young adults; ICl, immune-checkpoint inhibitor; irAE, immune-related adverse event; KDIGO, Kidney Disease: Improving Global Outcomes Work Group. ${ }^{a}$ With the exception of transverse myelitis and some other neurological, haematological and cardiac toxicities. ${ }^{b}$ Caution is advised, especially in patients with irAEs after one dose of ICls. ${ }^{c}$ With the exception of grade IV endocrinopathies that have been controlled by hormone replacement.

adults ${ }^{158,159}$. State-of-the-art biomarkers, such as circulating tumour DNA, could help distinguish between pseudoprogression and true progressive disease $\mathrm{e}^{158}$. A tissue biopsy, when feasible and safe, might more definitively enable an accurate diagnosis. For example, the presence of $\mathrm{CD}^{+}, \mathrm{CD}^{+}$, TIA $1^{+}$and granzyme $\mathrm{B}^{+}$ lymphocyte infiltrates suggests $\mathrm{T}$ cell activation induced by treatment, and thus indicates pseudoprogression ${ }^{160-162}$. In some patients, discontinuation of immunotherapy can be recommended if symptomatic pseudoprogression occurs, while other patients with clinical deterioration might benefit from continued treatment. Limited evidence is currently available to direct standard management recommendations and thus, the risk of clinically significant deterioration should be determined by the treating team until further evidence-based recommendations are available ${ }^{163}$.

\section{Nursing and critical care considerations}

Interdisciplinary and frontline clinical staff must demonstrate competency in prompt recognition of immunotherapy-associated complications and the use of the available clinical care algorithms to facilitate rapid escalation of care when indicated ${ }^{2,85}$. Consideration of important differential diagnoses are vital and assessment algorithms should be updated with emerging data. For example, distinction of blood transfusion reactions from CRS can be challenging if a patient develops signs or symptoms during the expected CRS window $^{164}$. In the USA, IEC centre accreditation by the Foundation for the Accreditation of Cellular Therapy (FACT) is recommended as a means to ensure optimal outcomes. Additionally, interprofessional education and simulation-based training can help cultivate a collaborative approach to patient-centred care in a safe and non-threatening environment ${ }^{165,166}$.
As the availability of and indications for cancer immunotherapies continue to expand, institutions might need to revise their clinical algorithms, admission policies, therapeutic strategies and staff training requirements ${ }^{98,167}$. Commonly reported reasons for critical care admission include grade 3-4 toxicities, organ failure, a need for closer monitoring, increasing oxygen requirements concerning for non-cardiogenic pulmonary oedema, rapid clinical deterioration owing to large tumour burden, concurrent ICANS and CRS, and/or lack of availability of a unit delivering intermediate care. In a phase I/IIa study in which 75 children and AYAs with B-ALL received tisagenlecleucel, the critical care admission rate was $47 \% ; 25 \%$ of these patients required high-dose vasopressors, $44 \%$ oxygen supplementation, $13 \%$ mechanical ventilation and $9 \%$ dialysis $^{87}$. In a retrospective study of adults with lymphoma who received axicabtagene ciloleucel, the critical care admission rates were high, but overall resource utilization was not disproportionate when compared with other patients with lymphoma who required critical care support during the same time period ${ }^{168}$. The availability of standardized clinical algorithms in conjunction with the presence of an interdisciplinary team can ensure the best possible patient outcomes ${ }^{98}$. An interdisciplinary expert panel, in which some authors of this Consensus Statement are involved, is currently assessing the role of extracorporeal therapies, such as extracorporeal membrane oxygenation, in paediatric patients receiving immunotherapies.

\section{Infection prophylaxis and treatment}

Considerations regarding infectious disease management (Supplementary Table 2) and prophylaxis (Supplementary Table 3) are important for teams administering immunotherapies to children and AYAs ${ }^{169}$. 
Patients with an increased risk of opportunistic infection owing to pre-existing neutropenia and/or hypogammaglobulinaemia (following prior treatments and/or lymphodepletion) would benefit from infectious disease surveillance screening and/or prophylaxis for viral, fungal and bacterial infections ${ }^{170,171}$. Additionally, patients receiving therapies targeting $B$ cells could be at increased risk of infection, notably sinopulmonary infection with encapsulated bacteria ${ }^{172}$. Patients who develop CRS and/or receive immunosuppressive cytokine blockade therapies might have longer-term immune dysfunction and benefit from prophylaxis for infections ${ }^{173}$. An important goal of common immunization programmes to prevent childhood infections is the induction of persistent protective levels of pathogen-specific antibodies ${ }^{174}$. Repletion of IVIG might be particularly important for paediatric patients with hypogammaglobulinaemia following cancer immunotherapy, given the smaller plasma volume and lower number of plasma cells in younger children and hence their decreased pathogen-specific immunity compared with adults ${ }^{173,175}$.

Further evidence is required before specific guidelines on vaccination after IEC therapy can be proposed, although we recommend that all patients are offered the seasonal influenza vaccine regardless of the level of immunosuppression, unless known contraindications exist. Other routine vaccines can be delayed in patients with platelet counts $<30,000$ cells $/ \mu$ l, those with active bleeding issues and those who have received $B$ cell-targeted antibodies and/or ICIs within the past 6 months. At present, no further standard recommendations regarding vaccination of children and AYAs receiving CAR $\mathrm{T}$ cell therapies are available. The use of live vaccines is not recommended within 5 months of receiving IVIG or plasma transfusion. Owing to the risk of long-term B cell aplasia (BCA), careful assessment of immune reconstitution and specific antibody responses to vaccines is recommended to help guide re-vaccination decisions $^{176}$.

During the COVID-19 pandemic, protocols for cancer immunotherapy eligibility and SARS-CoV-2 infection prevention, screening and management should be established locally and reviewed regularly in the context of infectious epidemiology and available resources ${ }^{177}$. Testing for SARS-CoV-2 infection should be considered before leukapheresis and initiation of lymphodepletion and/or cancer immunotherapy. From 2020, donors who have travelled to areas with prevalent SARS-CoV-2 infection, had known exposure to the virus and/or are actively infected, should have their cell collections postponed if possible ${ }^{177}$. Allogeneic products and/or products that are cryopreserved for manufacture are preferable to shipment of fresh products during periods of uncertain travel restrictions. While the data available are limited, children with cancer receiving immunotherapies might present with delayed and/or atypical and/or mild symptoms of SARS-CoV-2 infection ${ }^{178}$. High vigilance to distinguish primary disease progression from SARS-CoV-2 infection on radiological images is important. In some cases, repeat upper airway testing and/or lower airway testing might be indicated if a high degree of suspicion exists ${ }^{179}$. Antibody testing might not be reliable to establish a prior infection and/or determine immunity from reactivation and/or recurrence if the patient has $\mathrm{BCA}^{180}$. Prompt and accurate diagnosis of SARS-CoV-2 infection is important to ensure adequate infection control.

\section{Considerations on late effects}

Cancer immunotherapies have improved the likelihood of durable remission, especially among children with high-risk, R/R malignancies. To maximize clinical outcomes, sufficient attention must be paid to screening, diagnosis and management of potential late effects starting as early as 1 month after treatment initiation. Patients should be screened for secondary malignancies, ectopic tissue formation, immune reconstitution, organ dysfunction and endocrinopathies. Ruark et al. found that $37.5 \%$ of 40 AYAs and adults had one or more cognitive difficulties at a median of 3 years (range $1-5$ years) after CAR T cell therapy; these neurological effects along with other long-term psychological and quality-of-life outcomes need further evaluation ${ }^{181}$. Additionally, we recommend screening for primary disease recurrence, and/or consideration of consolidative therapies as available and when appropriate. For example, following CD19-targeted directed CAR therapies, up to $30 \%$ of patients can experience grade 3-4 cytopenias, not resolved by day 28 after therapy ${ }^{87}$. Thus, transfusions and/or growth factor support might be indicated, as well as a diagnostic bone marrow assessment to rule out other causes (such as myelodysplasia, malignancy, CAR T cell-related HLH or infection). Serial evaluation with bone marrow aspiration and MRD assessment by flow cytometry, quantitative PCR or next-generation sequencing at 3-month intervals might be appropriate. The presence of $\mathrm{CD} 19^{+}$haematogones can precede a rise in the number of peripheral $\mathrm{CD} 19^{+} \mathrm{B}$ cells and raise concern for loss of $\mathrm{BCA}^{182}$. Loss of BCA before 6 months after starting therapy is associated with increased risk of relapse and thus, further consolidative therapy should be strongly considered, including allogeneic $\mathrm{HSCT}^{183}$. BCA has been associated with progressive multifocal leukoencephalopathy and, therefore, patients should be monitored for neuropsychological, visual and motor deficits along with progressive dementia, which is suggestive of this condition, until BCA resolves ${ }^{184}$.

\section{Future directions}

As the landscape of paediatric cancer immunotherapies continues to rapidly evolve, involved parties must remain prepared to adapt accordingly. Payors and regulatory agencies have the ethical responsibility to promote early inclusion of children and AYAs in clinical trials of cancer immunotherapies to ensure access of these populations to potentially life-saving therapies. Given the rarity of paediatric and AYA cancers, whenever possible, all patients should be treated in a well-designed clinical trial ${ }^{185}$. Planned and ongoing clinical trials have the potential to radically alter the standard-of-care treatment for some childhood cancers. For example, the current duration of standard chemotherapy in children and AYAs with high-risk ALL is $\sim 2-3$ years. Patients with persistent MRD after induction and consolidation 
therapies are candidates for remission consolidation with high-dose chemoradiotherapy and allogeneic HSCT. An ongoing phase II clinical trial is testing upfront treatment with tisagenlecleucel after two or three cycles of chemotherapy in newly diagnosed children and AYAs with high-risk disease and persistent MRD after induction and consolidation chemotherapy (NCT03876769). The ZUMA-4 trial is testing axicabtagene in children and AYAs with precursor B cell malignancies R/R after one or more lines of systemic therapy, including those with MRD-positive disease (NCT02625480). The use of CAR T cells in patients with very high-risk disease after a few cycles of systemic chemotherapy might be associated with durable remissions and less cumulative exposure to cytotoxic agents (including intrathecal chemotherapy and radiation) that could have substantial long-term developmental effects, including on neurocognitive function ${ }^{186,187}$. CD19- relapse remains an important problem following immunotherapy with the CD19-targeted CAR T cell products. CD22 is a surface molecule expressed by most blasts in a majority (60-90\%) of patients with B-ALL and is a reasonable target in B lymphoid malignancies ${ }^{188-190}$. Many ongoing preclinical and clinical strategies targeting molecules other than CD19, such as CD22, are being evaluated in these patients; however, a discussion of these approaches is beyond the scope of this Consensus Statement.

\section{Conclusions}

Rapidly emerging cancer immunotherapies continue to positively and dramatically alter treatment paradigms in children and AYAs. These therapies are associated with promising outcomes in patients with high-risk disease, but also with unique and potentially lethal complications. The use of interdisciplinary clinical algorithms that recognize physiological and developmental characteristics of paediatric and AYA patients is required to optimize both short-term and long-term patient outcomes.

\section{Published online 19 February 2021}

1. Palmer, S., Patterson, P. \& Thompson, K. A national approach to improving adolescent and young adult (AYA) oncology psychosocial care: the development of AYA-specific psychosocial assessment and care tools. Palliat. Support. Care 12, 183-188 (2014).

2. Mahadeo, K. M. et al. Management guidelines for paediatric patients receiving chimeric antigen receptor T cell therapy. Nat. Rev. Clin. Oncol. 16, 45-63 (2019)

3. Lee, D. W. et al. ASTCT consensus grading for cytokine release syndrome and neurologic toxicity associated with immune effector cells. Biol. Blood Marrow Transpl. 25, 625-638 (2019).

4. FDA. Highlights of Prescribing Information: KYMRIAH https://www.fda.gov/files/vaccines, \%20blood $\% 20$ ¿\%20biologics/published/Package-Insert---KYMRIAH pdf (2018).

5. FDA. Highlights of Prescribing Information: YESCARTA https://www.fda.gov/media/108377/download (2020).

6. FDA. Highlights of Prescribing Information: TECARTUS https://www.fda.gov/media/140409/download (2020).

7. Brudno, J. N. \& Kochenderfer, J. N. Toxicities of chimeric antigen receptor T cells: recognition and management. Blood 127, 3321-3330 (2016).

8. Li, D. et al. Genetically engineered T cells for cance immunotherapy. Signal. Transduct. Target. Ther. $\mathbf{4}$ 35 (2019).

9. Johnson, L. A. \& June, C. H. Driving gene-engineered T cell immunotherapy of cancer. Cell Res. 27, 38-58 (2017).

10. Baiden-Amissah, R. E. M. \& Tuyaerts, S Contribution of aging, obesity, and microbiota on tumor immunotherapy efficacy and toxicity. Int. J. Mol. Sci. 20, 3586 (2019)

11. Ruella, M. \& Maus, M. V. Catch me if you can: leukemia escape after CD19-directed T cell immunotherapies. Comput. Struct. Biotechnol. J. 14, 357-362 (2016).

12. Fousek, K. et al. CAR T-cells that target acute B-lineage leukemia irrespective of CD19 expression. Leukemia 35, 75-89 (2021).

13. György, B. Bispecific CAR T cells have a dual grasp on tumors. Sci. Transl. Med. 12, eabf2636 (2020).

14. Liu, E. et al. Use of CAR-transduced natural killer cells in CD19-positive lymphoid tumors. N. Engl. J. Med. 382, 545-553 (2020).

15. Ghorashian, S. et al. Enhanced CAR T cell expansion and prolonged persistence in pediatric patients with ALL treated with a low-affinity CD19 CAR. Nat. Med. 25, 1408-1414 (2019).

16. Benjamin, R. et al. Genome-edited, donor-derived allogeneic anti-CD1 9 chimeric antigen receptor $T$ cells in paediatric and adult B-cell acute lymphoblastic leukaemia: results of two phase 1 studies. Lancet 396 1885-1894 (2020).

17. Grivennikov, S. I., Greten, F. R. \& Karin, M. Immunity, inflammation, and cancer. Cell 140, 883-899 (2010).

18. Scott, M. C. et al. Comparative transcriptome analysis quantifies immune cell transcript levels, metastatic progression, and survival in osteosarcoma. Cancer Res. 78, 326-337 (2018).
19. Serrels, A. et al. Nuclear FAK controls chemokine transcription, Tregs, and evasion of anti-tumor immunity. Cell 163, 160-173 (2015).

20. Rosenberg, S. A. et al. Use of tumor-infiltrating lymphocytes and interleukin-2 in the immunotherapy of patients with metastatic melanoma. N. Engl. J. Med. 319, 1676-1680 (1988)

21. Lizee, G. et al. Harnessing the power of the immune system to target cancer. Annu. Rev. Med. 64, 71-90 (2013).

22. Gattinoni, L., Powell, D. J. Jr., Rosenberg, S. A $\&$ Restifo, N. P. Adoptive immunotherapy for cancer: building on success. Nat. Rev. Immunol. 6, 383-393 (2006).

23. Wang, Z., Li, B., Ren, Y. \& Ye, Z. T-cell-based immunotherapy for osteosarcoma: challenges and opportunities. Front. Immunol. 7, 353 (2016).

24. Rosenberg, S. A. et al. Durable complete responses in heavily pretreated patients with metastatic melanoma using T-cell transfer immunotherapy. Clin. Cancer Res. 17, 4550-4557 (2011)

25. Dudley, M. E. et al. Cancer regression and autoimmunity in patients after clonal repopulation with antitumor lymphocytes. Science 298, 850-854 (2002).

26. Rosenberg, S. A. et al. Treatment of patients with metastatic melanoma with autologous tumor-infiltrating lymphocytes and interleukin 2. J. Natl Cancer Inst. 86, 1159-1166 (1994)

27. Parkhurst, M. R. et al. Unique neoantigens arise from somatic mutations in patients with gastrointestinal cancers. Cancer Discov 9, 1022-1035 (2019).

28. Turajlic, S. et al. Insertion-and-deletion-derived tumour-specific neoantigens and the immunogenic phenotype: a pan-cancer analysis. Lancet Oncol. 18, 1009-1021 (2017).

29. Olle Hurtado, M. et al. Tumor infiltrating lymphocytes expanded from pediatric neuroblastoma display heterogeneity of phenotype and function. PLOS ONE 14, e0216373 (2019).

30. Mullinax, J. E. et al. Combination of ipilimumab and adoptive cell therapy with tumor-infiltrating lymphocytes for patients with metastatic melanoma. Front. Oncol. 8, 44 (2018).

31. Zhao, Q. et al. Tumor-targeted IL-12 combined with tumor resection yields a survival-favorable immune profile. J. Immunother Cancer 7,154 (2019).

32. Nguyen, L. T. et al. Phase II clinical trial of adoptive cell therapy for patients with metastatic melanoma with autologous tumor-infiltrating lymphocytes and low-dose interleukin-2. Cancer Immunol. Immunother 68, 773-785 (2019).

33. Schwinger, W. et al. Feasibility of high-dose interleukin- 2 in heavily pretreated pediatric cancer patients. Ann. Oncol. 16, 1199-1206 (2005).

34. Yeh, S. et al. Ocular and systemic autoimmunity after successful tumor-infiltrating lymphocyte immunotherapy for recurrent, metastatic melanoma. Ophthalmology 116, 981-989.e1 (2009).

35. Robbins, P. F. et al. A pilot trial using lymphocytes genetically engineered with an NY-ESO-1-reactive
T-cell receptor: long-term follow-up and correlates with response. Clin. Cancer Res. 21, 1019-1027 (2015).

36. Morgan, R. A. et al. Cancer regression and neurological toxicity following anti-MAGE-A3 TCR gene therapy. J. Immunother. 36, 133-151 (2013).

37. Linette, G. P. et al. Cardiovascular toxicity and titin cross-reactivity of affinity-enhanced T cells in myeloma and melanoma. Blood 122, 863-871 (2013).

38. Chodon, T. et al. Adoptive transfer of MART-1 T-cell receptor transgenic lymphocytes and dendritic cell vaccination in patients with metastatic melanoma. Clin. Cancer Res. 20, 2457-2465 (2014).

39. Tawara, I. et al. Safety and persistence of WT 1 -specific T-cell receptor gene-transduced lymphocytes in patients with AML and MDS. Blood 130, 1985-1994 (2017).

40. Rezvani, K., Rouce, R., Liu, E. \& Shpall, E. Engineering natural killer cells for cancer immunotherapy. Mol. Ther. 25, 1769-1781 (2017).

41. Khatua, S. et al. Phase I study of intraventricular infusions of autologous ex-vivo-expanded NK cells in children with recurrent medulloblastoma and ependymoma. Neuro Oncol. 22, 1214-1225 (2020)

42. Screpanti, V., Wallin, R. P., Ljunggren, H. G. $\&$ Grandien, A. A central role for death receptormediated apoptosis in the rejection of tumors by NK cells. J. Immunol. 167, 2068-2073 (2001).

43. Vela, M. et al. Haploidentical IL-15/41 BBL activated and expanded natural killer cell infusion therapy after salvage chemotherapy in children with relapsed and refractory leukemia. Cancer Lett. 422, 107-117 (2018).

44. Rubnitz, J. E. et al. NKAML: a pilot study to determine the safety and feasibility of haploidentical natural killer cell transplantation in childhood acute myeloid leukemia. J. Clin. Oncol. 28, 955-959 (2010).

45. Nguyen, R. et al. A phase II clinical trial of adoptive transfer of haploidentical natural killer cells for consolidation therapy of pediatric acute myeloid leukemia. J. Immunother. Cancer 7, 81 (2019).

46. Cho, D. et al. Cytotoxicity of activated natural killer cells against pediatric solid tumors. Clin. Cancer Res. 16, 3901-3909 (2010)

47. Fernandez, L. et al. Activated and expanded natural killer cells target osteosarcoma tumor initiating cells in an NKG2D-NKG2DL dependent manner. Cancer Lett. 368, 54-63 (2015).

48. Shah, N. N. et al. Acute GVHD in patients receiving IL-15/4-1BBL activated NK cells following T-cell-depleted stem cell transplantation. Blood 125, 784-792 (2015).

49. Pérez-Martínez, A. et al. Natural killer cells can exert a graft-vs-tumor effect in haploidentical stem cell transplantation for pediatric solid tumors. Exp. Hematol. 40, 882-891.e1 (2012).

50. Kimpo, M. S., Oh, B. \& Lee, S. The role of natural killer cells as a platform for immunotherapy in pediatric cancers. Curr. Oncol. Rep. 21, 93 (2019).

51. Denman, C. J. et al. Membrane-bound IL-21 promotes sustained ex vivo proliferation of human natural killer cells. PLoS ONE 7, e30264 (2012). 
52. Andersen, M. H., Schrama, D., thor Straten, P. \& Becker, J. C. Cytotoxic T cells. J. Invest. Dermatol. 126, 32-41 (2006)

53. Van Pel, A. \& Boon, T. Protection against a nonimmunogenic mouse leukemia by an immunogenic variant obtained by mutagenesis. Proc. Natl Acad. Sci. USA 79, 4718-4722 (1982)

54. Castelli, C. et al. T-cell recognition of melanomaassociated antigens. J. Cell. Physiol. 182, 323-331 (2000).

55. Liu, Z. et al. Epstein-Barr virus (EBV)-specific cytotoxic $T$ lymphocytes for the prevention and treatment of EBV-associated post-transplant lymphomas. Recent. Results Cancer Res. 159, 123-133 (2002).

56. Prockop, S. et al. Off-the-shelf EBV-specific T cell immunotherapy for rituximab-refractory EBV-associated lymphoma following transplantation. J. Clin. Invest. 130, 733-747 (2020).

57. Moosmann, A. et al. Effective and long-term control of EBV PTLD after transfer of peptide-selected T cells. Blood 115, 2960-2970 (2010).

58. Prockop, S. E. et al. A multicenter, open label, phase 3 study of tabelecleucel for solid organ transplant subjects with Epstein-Barr virus-driven post-transplant lymphoproliferative disorder (EBV+PTLD) after failure of rituximab or rituximab and chemotherapy (ALLELE) [abstract]. Biol. Blood Marrow Transpl. 26, S274 (2020).

59. Prockop, S. E. et al. Long-term outcomes of patients with epstein-barr virus-driven post-transplant lymphoproliferative disease following solid organ transplant or allogeneic hematopoietic cell transplant treated with tabelecleucel in a multicenter expanded access program study [abstract]. Biol. Blood Marrow Transpl. 26, S61-S62 (2020).

60. Bollard, C. M. et al. Cytotoxic T lymphocyte therapy for Epstein-Barr virus+Hodgkin's disease. J. Exp. Med. 200, 1623-1633 (2004)

61. Straathof, K. C. et al. Treatment of nasopharyngeal carcinoma with Epstein-Barr virus-specific T lymphocytes. Blood 105, 1898-1904 (2005).

62. Schuessler, A. et al. Autologous T-cell therapy for cytomegalovirus as a consolidative treatment for recurrent glioblastoma. Cancer Res. 74 , 3466-3476 (2014).

63. Leen, A. M. et al. Multicenter study of banked thirdparty virus-specific $\mathrm{T}$ cells to treat severe viral infections after hematopoietic stem cell transplantation. Blood 121, 5113-5123 (2013)

64. Gottschalk, S. \& Rooney, C. M. Adoptive T-cell immunotherapy. Curr. Top. Microbiol. Immunol. 391, 427-454 (2015).

65. Muftuoglu, M. et al. Allogeneic BK virus-specific T cells for progressive multifocal leukoencephalopathy. N. Engl. J. Med. 379, 1443-1451 (2018).

66. Pello, O. M. et al. BKV-specific T cells in the treatment of severe refractory haemorrhagic cystitis after HLAhaploidentical haematopoietic cell transplantation. Eur. J. Haematol. 98, 632-634 (2017).

67. Huehls, A. M., Coupet, T. A. \& Sentman, C. L. Bispecific T-cell engagers for cancer immunotherapy. Immunol. Cell Biol. 93, 290-296 (2015).

68. FDA. Highlights of Prescribing Information: Blincyto. https://www.accessdata.fda.gov/drugsatfda_docs/ label/2018/125557s013lbl.pdf (2018).

69. Boussiotis, V. A. Molecular and biochemical aspects of the PD-1 checkpoint pathway. N. Engl. J. Med. 375 1767-1778 (2016)

70. Toor, S. M. \& Elkord, E. Therapeutic prospects of targeting myeloid-derived suppressor cells and immune checkpoints in cancer. Immunol. Cell Biol. 96, 888-897 (2018).

71. Hargadon, K. M., Johnson, C. E. \& Williams, C. J. Immune checkpoint blockade therapy for cancer: an overview of FDA-approved immune checkpoint inhibitors. Int. Immunopharmacol. 62, 29-39 (2018)

72. Hodi, F. S. et al. Improved survival with ipilimumab in patients with metastatic melanoma. N. Engl. J. Med. 363, 711-723 (2010)

73. Merchant, M. S. et al. Phase I clinical trial of ipilimumab in pediatric patients with advanced solid tumors. Clin. Cancer Res. 22, 1364-1370 (2016).

74. Geoerger, B. et al. Phase II study of ipilimumab in adolescents with unresectable stage III or IV malignant melanoma. Eur. J. Cancer 86, 358-363 (2017).

75. Davis, K. L. et al. Nivolumab in children and young adults with relapsed or refractory solid tumours or lymphoma (ADVL1412): a multicentre, open-label, single-arm, phase 1-2 trial. Lancet Oncol. 21, 541-550 (2020)

76. Overman, M. J. et al. Nivolumab in patients with metastatic DNA mismatch repair-deficient or microsatellite instability-high colorectal cancer (CheckMate 142): an open-label, multicentre, phase 2 study. Lancet Oncol. 18, 1182-1191 (2017)

77. Overman, M. J. et al. Durable clinical benefit with nivolumab plus ipilimumab in DNA mismatch repair deficient/microsatellite instability-high metastatic colorectal cancer. J. Clin. Oncol. 36, 773-779 (2018)

78. Geoerger, B. et al. Pembrolizumab in paediatric patients with advanced melanoma or a PD-L1-positive, advanced, relapsed, or refractory solid tumour or lymphoma (KEYNOTE-051): interim analysis of an open-label, single-arm, phase 1-2 trial. Lancet Oncol. 21, 121-133 (2020)

79. Goldberg, S. B. et al. Pembrolizumab for management of patients with NSCLC and brain metastases: long-term results and biomarker analysis from a non-randomised, open-label, phase 2 trial. Lancet Oncol. 21, 655-663 (2020).

80. Kawazoe, A. et al. Lenvatinib plus pembrolizumab in patients with advanced gastric cancer in the first-line or second-line setting (EPOC1706): an open-label, single-arm, phase 2 trial. Lancet Oncol. 21, 1057-1065 (2020).

81. Grosser, R., Cherkassky, L., Chintala, N. \& Adusumilli, P. S. Combination immunotherapy with CAR T cells and checkpoint blockade for the treatmen of solid tumors. Cancer Cell 36, 471-482 (2019).

82. Ghosh, A. K. et al. CAR T cell therapy-related cardiovascular outcomes and management: systemic disease or direct cardiotoxicity? JACC 2, 97-109 (2020).

83. Feng, Y. et al. Exposure-response relationships of the efficacy and safety of ipilimumab in patients with advanced melanoma. Clin. Cancer Res. 19 3977-3986 (2013).

84. Ihara, K. Immune checkpoint inhibitor therapy for pediatric cancers: a mini review of endocrine adverse events. Clin. Pediatr. Endocrinol. 28, 59-68 (2019).

85. Neelapu, S. S. et al. Chimeric antigen receptor T-cell therapy - assessment and management of toxicities. Nat. Rev. Clin. Oncol. 15, 47-62 (2018).

86. Brahmer, J. R. et al. Management of immune-related adverse events in patients treated with immune checkpoint inhibitor therapy: American Society of Clinical Oncology Clinical Practice Guideline. J. Clin Oncol. 36, 1714-1768 (2018).

87. Maude, S. L. et al. Tisagenlecleucel in children and young adults with B-cell lymphoblastic leukemia. N. Engl. J. Med. 378, 439-448 (2018).

88. Queudeville, M. et al. Blinatumomab in pediatric patients with relapsed/refractory B-cell precursor acute lymphoblastic leukemia. Eur. J. Haematol. https://doi.org/10.1111/ejh.13569 (2020).

89. Berg, M. D. et al. Part 13: Pediatric basic life support 2010 American Heart Association Guidelines for Cardiopulmonary Resuscitation and Emergency Cardiovascular Care. Circulation 122, S862-S875 (2010).

90. Gutierrez, C. et al. Critical care management of toxicities associated with targeted agents and immunotherapies for cancer. Crit. Care Med. 48 , 10-21 (2020).

91. Fitzgerald, J. C. et al. Cytokine release syndrome after chimeric antigen receptor T cell therapy for acute lymphoblastic leukemia. Crit. Care Med. 45, e124-e131 (2017)

92. Roy, J. P. \& Devarajan, P. Acute kidney injury: diagnosis and management. Indian J. Pediatr. $\mathbf{8 7}$ 600-607 (2020)

93. Fragasso, T., Ricci, Z. \& Goldstein, S. L. in Contributions to Nephrology (eds Ding, X., Rosner, M. H. \& Ronco, C.) 113-126 (Karger, 2018). [Series Ed. Ronco, C. Acute Kidney Injury - Basic Research and Clinical Practice Vol. 193]

94. Menon, S. et al. Urinary biomarker incorporation into the renal angina index early in intensive care unit admission optimizes acute kidney injury prediction in critically ill children: a prospective cohort study. Nephrol. Dial. Transpl. 31, 586-594 (2016).

95. Bottari, G. et al. Multimodal therapeutic approach of cytokine release syndrome developing in a child given chimeric antigen receptor-modified $\mathrm{T}$ cell infusion. Crit. Care Explor. 2, e0071 (2020).

96. Gutgarts, V. et al. Acute kidney injury after CAR-T cell therapy: low incidence and rapid recovery. Biol. Blood Marrow Transpl. 26, 1071-1076 (2020).

97. Gupta, S. et al. Acute kidney injury and electrolyte abnormalities after chimeric antigen receptor T-cell (CAR-T) therapy for diffuse large B-cell lymphoma. Am. J. Kidney Dis. 76, 63-71 (2020)

98. Gutierrez, C. et al. The chimeric antigen receptorintensive care unit (CAR-ICU) initiative: surveying intensive care unit practices in the management of CAR T-cell associated toxicities. J. Crit. Care $\mathbf{5 8}$, 58-64 (2020).

99. Dubois, M. J. et al. Albumin administration improves organ function in critically ill hypoalbuminemic patients: a prospective, randomized, controlled, pilot study. Crit. Care Med. 34, 2536-2540 (2006).

100. Hariri, G. et al. Albumin infusion improves endothelial function in septic shock patients: a pilot study. Intensive Care Med. 44, 669-671 (2018).

101. Hu, Y., Feng, J., Shao, M. \& Huang, H. Profile of capillary-leak syndrome in patients received chimeric antigen receptor T cell therapy [abstract]. Blood 132 (Suppl. 1), 5204 (2018)

102. Milesi, C. et al. High-flow nasal cannula: recommendations for daily practice in pediatrics. Ann. Intensive Care 4, 29 (2014)

103. Dysart, K., Miller, T. L., Wolfson, M. R. \& Shaffer, T. H. Research in high flow therapy: mechanisms of action. Respir. Med. 103, 1400-1405 (2009).

104. McDonald, C. F. Low-flow oxygen: how much is your patient really getting? Respirology 19, 469-470 (2014).

105. Kwon, J. W. High-flow nasal cannula oxygen therapy in children: a clinical review. Clin. Exp. Pediatr. 63, 3-7 (2020).

106. Hutchings, F. A., Hilliard, T. N. \& Davis, P. J. Heated humidified high-flow nasal cannula therapy in children. Arch. Dis. Child. 100, 571-575 (2015).

107. Weiler, T. et al. The relationship between high flow nasal cannula flow rate and effort of breathing in children. J. Pediatr. 189, 66-71.e3 (2017).

108. Morley, S. L. Non-invasive ventilation in paediatric critical care. Paediatr. Respir. Rev. 20, 24-31 (2016)

109. Morris, J. V., Kapetanstrataki, M., Parslow, R. C., Davis, P. J. \& Ramnarayan, P. Patterns of use of heated humidified high-flow nasal cannula therapy in PICUs in the United Kingdom and Republic of Ireland. Pediatr. Crit. Care Med. 20, 223-232 (2019).

110. Mestermann, K. et al. The tyrosine kinase inhibitor dasatinib acts as a pharmacologic on/off switch for CAR T cells. Sci. Transl. Med. 11, eaau5907 (2019).

111. Philip, B. RQR8: A universal safety switch for cellular therapies. Thesis, University College London (2015).

112. Gardner, R. A. et al. Preemptive mitigation of CD 19 CAR T-cell cytokine release syndrome without attenuation of antileukemic efficacy. Blood 134, 2149-2158 (2019).

113. Kadauke, S. et al. Early administration of tocilizumab (Toci) for the prevention of grade 4 cytokine release syndrome (CRS) after CD19-directed CAR T-cell therapy (CTL019) [abstract]. Cytotherapy 21, e2-e3 (2019).

114. Yanez, L., Sanchez-Escamilla, M. \& Perales, M. A. CAR T cell toxicity: current management and future directions. Hemasphere 3, e186 (2019).

115. Schuster, S. J. et al. Chimeric antigen receptor T cells in refractory B-cell lymphomas. N. Engl. J. Med. 377 , 2545-2554 (2017).

116. Neelapu, S. S. et al. Axicabtagene ciloleucel CAR T-cel therapy in refractory large B-cell lymphoma. N. Engl. J. Med. 377, 2531-2544 (2017).

117. Mahadeo, K. M. et al. Diagnosis, grading, and treatment recommendations for children, adolescents, and young adults with sinusoidal obstructive syndrome: an international expert position statement. Lancet Haematol. 7, e61-e72 (2020).

118. Gust, J. et al. Glial injury in neurotoxicity after pediatric CD19-directed chimeric antigen receptor T cell therapy. Ann. Neurol. 86, 42-54 (2019).

119. Gust, J. et al. Endothelial activation and blood-brain barrier disruption in neurotoxicity after adoptive immunotherapy with CD19 CAR-T cells. Cancer Discov. 7, 1404-1419 (2017)

120. Santomasso, B. D. et al. Clinical and biological correlates of neurotoxicity associated with CAR T-cell therapy in patients with B-cell acute lymphoblastic leukemia. Cancer Discov. 8, 958-971 (2018).

121. Miettunen, P. M., Narendran, A., Jayanthan, A., Behrens, E. M. \& Cron, R. Q. Successful treatment of severe paediatric rheumatic disease-associated macrophage activation syndrome with interleukin-1 inhibition following conventional immunosuppressive therapy: case series with 12 patients. Rheumatology 50, 417-419 (2011).

122. Henter, J. I. et al. HLH-2004: Diagnostic and therapeutic guidelines for hemophagocytic lymphohistiocytosis. Pediatr. Blood Cancer 48 124-131 (2007)

123. Brudno, J. N. et al. Allogeneic T cells that express an anti-CD 19 chimeric antigen receptor induce remissions of B-cell malignancies that progress after allogeneic hematopoietic stem-cell transplantation without 
causing graft-versus-host disease. J. Clin. Oncol. 34, 1112-1121 (2016)

124. Glucksberg, H. et al. Clinical manifestations of graftversus-host disease in human recipients of marrow from HL-A-matched sibling donors. Transplantation 18, 295-304 (1974).

125. Jacobsohn, D. Acute graft-versus-host disease in children. Bone Marrow Transplant. 41, 215-221 (2008).

126. Harris, A. C. et al. International, multicenter standardization of acute graft-versus-host disease clinical data collection: a report from the Mount Sinai Acute GVHD International Consortium. Biol. Blood Marrow Transpl. 22, 4-10 (2016).

127. Li, X., Shao, C., Shi, Y. \& Han, W. Lessons learned from the blockade of immune checkpoints in cancer immunotherapy. J. Hematol. Oncol. 11, 31 (2018).

128. Liu, Y. H. et al. Diagnosis and management of immune related adverse events (irAEs) in cancer immunotherapy. Biomed. Pharmacother. 120, 109437 (2019).

129. Khan, M. et al. Comparative analysis of immune checkpoint inhibitors and chemotherapy in the treatment of advanced non-small cell lung cancer: a meta-analysis of randomized controlled trials. Medicine 97, e11936 (2018).

130. de La Rochefoucauld, J., Noel, N. \& Lambotte, O. Management of immune-related adverse events associated with immune checkpoint inhibitors in cancer patients: a patient-centred approach. Intern. Emerg. Med. 15, 587-598 (2020)

131. Weber, J. S., Kahler, K. C. \& Hauschild, A. Management of immune-related adverse events and kinetics of response with ipilimumab. J. Clin. Oncol. 30 , 2691-2697 (2012)

132. Li, A. M. et al. Checkpoint inhibitors augment CD19directed chimeric antigen receptor (CAR) T cell therapy in relapsed B-cell acute lymphoblastic leukemia [abstract]. Blood 132 (Suppl. 1), 556 (2018).

133. Bajciova, V. Therapeutic effect and tolerance of ipilimumam in metastatic malignant melanoma in children - a case report. Klin. Onkol. 28, 4S115-4S120 (2015).

134. Blumenthal, D. T. et al. Pembrolizumab: first experience with recurrent primary central nervous system (CNS) tumors. J. Neurooncol 129, 453-460 (2016)

135. Bouffet, E. et al. Immune checkpoint inhibition for hypermutant glioblastoma multiforme resulting from germline biallelic mismatch repair deficiency. J. Clin. Oncol. 34, 2206-2211 (2016).

136. Foran, A. E., Nadel, H. R., Lee, A. F., Savage, K. J. $\&$ Deyell, R. J. Nivolumab in the treatment of refractory pediatric Hodgkin lymphoma. J. Pediatr. Hematol. Oncol. 39, e263-e266 (2017).

137. Shad, A. T. et al. Tolerance and effectiveness of nivolumab after pediatric T-cell replete, haploidentical, bone marrow transplantation: a case report. Pediatr. Blood Cancer 64, e26257 (2017).

138. Zhu, X. et al. Severe cerebral edema following nivolumab treatment for pediatric glioblastoma: case report. J. Neurosurg. Pediatr. 19, 249-253 (2017).

139. Postow, M. A., Sidlow, R. \& Hellmann, M. D. Immunerelated adverse events associated with immune checkpoint blockade. N. Engl. J. Med. 378, 158-168 (2018).

140. Weber, J. S., Yang, J. C., Atkins, M. B. \& Disis, M. L. Toxicities of immunotherapy for the practitioner. J. Clin. Oncol. 33, 2092-2099 (2015).

141. Trinh, S., Le, A., Gowani, S. \& La-Beck, N. M. Management of immune-related adverse events associated with immune checkpoint inhibitor therapy: a minireview of current clinical guidelines. Asia Pac. J. Oncol. Nurs. 6, 154-160 (2019).

142. Livingston, E. H. \& Lee, S. Percentage of burned body surface area determination in obese and nonobese patients. J. Surg. Res. 91, 106-110 (2000).

143. Ham, P. \& Allen, C. Adolescent health screening and counseling. Am. Fam. Phys. 86, 1109-1116 (2012).

144. Clotman, K., Janssens, K., Specenier, P., Weets, I. $\&$ De Block, C. E. M. Programmed cell death-1 inhibitor-induced type 1 diabetes mellitus. J. Clin. Endocrinol. Metab. 103, 3144-3154 (2018).

145. Stamatouli, A M et al. Collateral damage: insulin-dependent diabetes induced with checkpoint inhibitors. Diabetes 67, 1471-1480 (2018).

146. Sakamoto, K., Fukihara, J., Morise, M. \& Hashimoto, N. Clinical burden of immune checkpoint inhibitor-induced pneumonitis. Respir. Investig. 58, 305-319 (2020).

147. Naidoo, J. et al. Pneumonitis in patients treated with anti-programmed death-1/programmed death ligand 1 therapy. J. Clin. Oncol. 35, 709-717 (2017).

148. Rashdan, S., Minna, J. D. \& Gerber, D. E. Diagnosis and management of pulmonary toxicity associated with cancer immunotherapy. Lancet Respir. Med. 6 , 472-478 (2018)

149. Khwaja, A. KDIGO clinical practice guideline for acute kidney injury. Nephron. Clin. Pract. 120, c179-c184 (2012).

150. Gupta, S., Cortazar, F. B., Riella, L. V. \& Leaf, D. E. Immune checkpoint inhibitor nephrotoxicity: update 2020. Kidney360 1, 130-140 (2020).

151. Ma, Y., Wang, Q., Dong, Q., Zhan, L. \& Zhang, J. How to differentiate pseudoprogression from true progression in cancer patients treated with immunotherapy. $\mathrm{Am}$. J. Cancer Res. 9, 1546-1553 (2019).

152. Ferrara, R. et al. Do immune checkpoint inhibitors need new studies methodology? J. Thorac. Dis. 10, S1564-S1580 (2018).

153. Eisenhauer, E. A. et al. New response evaluation criteria in solid tumours: revised RECIST guideline (version 1.1). Eur. J. Cancer 45, 228-247 (2009).

154. Nishino, M. et al. Developing a common language for tumor response to immunotherapy: immune-related response criteria using unidimensional measurements. Clin. Cancer Res. 19, 3936-3943 (2013).

155. Pignon, J.-C. et al. irRECIST for the evaluation of candidate biomarkers of response to nivolumab in metastatic clear cell renal cell carcinoma: analysis of a phase II prospective clinical trial. Clin. Cancer Res. 25, 2174-2184 (2019).

156. Seymour, L. et al. iRECIST: guidelines for response criteria for use in trials testing immunotherapeutics. Lancet Oncol. 18, e143-e152 (2017).

157. Wolchok, J. D. et al. Guidelines for the evaluation of immune therapy activity in solid tumors: immunerelated response criteria. Clin. Cancer Res. 15, 7412-7420 (2009).

158. Lee, J. H. et al. Association between circulating tumor DNA and pseudoprogression in patients with metastatic melanoma treated with anti-programmed cell death 1 antibodies. JAMA Oncol. 4, 717-721 (2018).

159. Okada, H. et al. Immunotherapy response assessment in neuro-oncology: a report of the RANO working group. Lancet Oncol. 16, e534-e542 (2015).

160. Di Giacomo, A. M. et al. Therapeutic efficacy of ipilimumab, an anti-CTLA-4 monoclonal antibody, in patients with metastatic melanoma unresponsive to prior systemic treatments: clinical and immunological evidence from three patient cases. Cancer Immunol. Immunother. 58, 1297-1306 (2009).

161. Masuhiro, K., Shiroyama, T., Nagatomo, I. \& Kumanogoh, A. Unique case of pseudoprogression manifesting as lung cavitation after pembrolizumab treatment. J. Thorac. Oncol. 14, e108-e109 (2019).

162. Tanizaki, J. et al. Report of two cases of pseudoprogression in patients with non-small cell lung cancer treated with nivolumab-including histological analysis of one case after tumor regression. Lung Cancer 102, 44-48 (2016).

163. Hochmair M. J. Schwab S., Burghuber O C. Krenbek, D. \& Prosch, H. Symptomatic pseudoprogression followed by significant treatment response in two lung cancer patients treated with immunotherapy. Lung Cancer 113, 4-6 (2017).

164. Kohorst, M. A. et al. Transfusion reactions in pediatric and adolescent young adult haematology oncology and immune effector cell patients. EClinicalMedicine 26, 100514 (2020).

165. Kim, J., Park, J. H. \& Shin, S. Effectiveness of simulation-based nursing education depending on fidelity: a meta-analysis. BMC Med. Educ. 16, 152 (2016).

166. Okuda, Y. et al. The utility of simulation in medical education: what is the evidence? Mt. Sinai J. Med. $\mathbf{7 6}$ 330-343 (2009).

167. Azoulay, E., Shimabukuro-Vornhagen, A., Darmon, M $\&$ von Bergwelt-Baildon, M. Critical care management of chimeric antigen receptor $\mathrm{T}$ cell-related toxicity. Be aware and prepared. Am. J. Respir. Crit. Care Med. 200, 20-23 (2019).

168. $r$ ICU resource utilization in critically ill patients following chimeric antigen receptor T-cell therapy. Am. J. Respir Crit. Care Med. 202, 1184-1187 (2020)

169. Redelman-Sidi, G. et al. ESCMID Study Group for Infections in Compromised Hosts (ESGICH) Consensus Document on the safety of targeted and biological therapies: an infectious diseases perspective (immune checkpoint inhibitors, cell adhesion inhibitors, sphingosine-1-phosphate receptor modulators and proteasome inhibitors). Clin. Microbiol. Infect. 24 S95-S107 (2018).

170. Davies, H. D \& Committee on Infectious Diseases. Infectious complications with the use of biologic response modifiers in infants and children. Pediatrics 138, e20161209 (2016).
171. Hill, J. A. \& Seo, S. K. How I prevent infections in patients receiving CD19-targeted chimeric antigen receptor T cells for B-cell malignancies. Blood 136, 925-935 (2020).

172. Fishman, J. A., Hogan, J. I. \& Maus, M. V. Inflammatory and infectious syndromes associated with cancer immunotherapies. Clin. Infect. Dis. 69, 909-920 (2019).

173. Yakoub-Agha, I. et al. Management of adults and children undergoing CAR T-cell therapy: best practice recommendations of the European Society for Blood and Marrow Transplantation (EBMT) and the Joint Accreditation Committee of ISCT and EBMT (JACIE). Haematologica 105, 297-316 (2019).

174. Kelly, D. F. et al. Plasma and memory B-cell kinetics in infants following a primary schedule of CRM 197-conjugated serogroup $\mathrm{C}$ meningococcal polysaccharide vaccine. Immunology 127, 134-143 (2009).

175. Perez, E. E. et al. Update on the use of immunoglobulin in human disease: a review of evidence. J. Allergy Clin. Immunol. 139, S1-S46 (2017).

176. Tomblyn, M. et al. Guidelines for preventing infectious complications among hematopoietic cell transplantation recipients: a global perspective. Biol. Blood Marrow Transpl. 15, 1143-1238 (2009).

177. Hu, Y. et al. CAR T-cell treatment during the COVID-19 pandemic: management strategies and challenges. Curr. Res. Transl. Med. 68, 111-118 (2020).

178. Bisogno, G. et al. Clinical characteristics and outcome of severe acute respiratory syndrome coronavirus 2 infection in Italian pediatric oncology patients: a study from the Infectious Diseases Working Group of the Associazione Italiana di Oncologia e Ematologia Pediatrica. J. Pediatric Infect. Dis. Soc. 9, 530-534 (2020).

179. Mohammadi, A., Esmaeilzadeh, E., Li, Y. Bosch, R. J. \& Li, J. Z. SARS-CoV-2 detection in different respiratory sites: a systematic review and meta-analysis. EbioMedicine 59, 102903 (2020).

180. Zhou, X., Zhou, J. \& Zhao, J. Recurrent pneumonia in a patient with new coronavirus infection after discharge from hospital for insufficient antibody production: a case report. BMC Infect. Dis. 20, 500 (2020)

181. Ruark, J. et al. Patient-reported neuropsychiatric outcomes of long-term survivors after chimeric antigen receptor T cell therapy. Biol. Blood Marrow Transpl. 26, 34-43 (2020).

182. Broome, H. E., Rassenti, L. Z., Wang, H. Y., Meyer, L. M $\&$ Kipps, T. J. ROR1 is expressed on hematogones (non-neoplastic human B-lymphocyte precursors) and a minority of precursor-B acute lymphoblastic leukemia. Leuk. Res. 35, r-1394 (2011).

183. Mueller, K. T. et al. Clinical pharmacology of tisagenlecleucel in B-cell acute lymphoblastic leukemia. Clin. Cancer Res. 24, 6175-6184 (2018).

184 . Weissert, R. Progressive multifocal leukoencephalopathy. J. Neuroimmunol. 231, 73-77 (2011).

185. Brown, P. et al. Pediatric acute lymphoblastic leukemia, version 2.2020, NCCN Clinical Practice Guidelines in Oncology. J. Natl Compr. Canc Netw. 18, 81-112 (2020).

186. Maude, S. L. et al. Efficacy of humanized CD19targeted chimeric antigen receptor (CAR)-modified T cells in children and young adults with relapsed/ refractory acute lymphoblastic leukemia [abstract]. Blood. 128, 217 (2016).

187. Maude, S. L. et al. Sustained remissions with CD19-specific chimeric antigen receptor (CAR)modified T cells in children with relapsed/refractory ALL [abstract]. J. Clin. Oncol. 34, 3011 (2016).

188. Lanza, $\mathrm{F}$ et al. CD22 expression in B-cell acute lymphoblastic leukemia: biological significance and implications for inotuzumab therapy in adults. Cancers 12, 303 (2020).

189. Fry, T. J. et al. CD22-targeted CAR T cells induce remission in B-ALL that is naive or resistant to CD19targeted CAR immunotherapy. Nat. Med. 24, 20-28 (2018).

190. Shah, N. N. et al. CD4/CD8 T-cell selection affects chimeric antigen receptor (CAR) T-cell potency and toxicity: updated results from a phase I anti-CD22 CAR T-cell trial. J. Clin. Oncol. 38, 1938-1950 (2020).

191. Neelapu, S. S. et al. Toxicity management after chimeric antigen receptor $\mathrm{T}$ cell therapy: one size does not fit 'ALL' Nat. Rev Clin Oncol 15, 218 (2018).

192. Dufner, V. et al. Long-term outcome of patients with relapsed/refractory B-cell non-Hodgkin lymphoma treated with blinatumomab. Blood Adv. 3, 2491-2498 (2019). 
193. Lund C. C. The estimation of areas of burns. Surg. Gynecol. Obste 79, 352-358 (1944).

\section{Acknowledgements}

We thank the MD Anderson Cancer Center CAR T Cell Therapy-Associated Toxicity (CARTOX) Program, The University of Texas MD Anderson Cancer Center, the Pediatric Acute Lung Injury and Sepsis Investigators (PALISI) Network Hematopoietic Cell Transplantation-Cancer Immunotherapy (HCT-Cl) Subgroup and the PALISI Network Scientific Committee, the Supportive Care Committee of the Pediatric Transplantation and Cellular Therapy Consortium (PTCTC), the Extracorporeal Life Support Organization (ELSO) and the Paediatric Diseases Working Party (PDWP) of the European Society of Blood and Marrow Transplantation (EBMT). D.R., S.J.K., D.MCC., B.C., B.S., J.M., P.T., D.P., F.N.H.T., P.K., K.R S.S.N, E.J.S. and K.M.M. are members of the CARTOX Program. H.A, A.H.A., M.D.N., B.S., M.E.S. and K.M.M. are members of the PALISI HCT-Cl subgroup. H.A.A., J.A S.W.C. and K.M.M are members of the PTCTC. M.D.N. is a member of ELSO. S.C. is a member of the PDWP of the EBMT. We thank our patients and families who inspire and guide us towards continuous improvement. We thank ou respective nursing unit staffs and key stakeholders who work to ensure access to novel therapies for our patients. C.M.R. is the recipient of a K23 grant (1K23HL150244) from the National Heart, Lung and Blood Institute.
Author contributions

D.R., S.J.K.,H.A., D.McC., A.H.A., B.C., C.G., L.C., B.S. R.D.S., E.J.S. and K.M.M. wrote the manuscript. All authors made meaningful contributions to and reviewed the manuscript.

\section{Competing interests}

C.G. has served on the advisory board for Janssen and Legend Biotech. A relative of J.B.G. is a consultant to Acceleron and Celgene. K.R. and E.J.S. have a licence agree ment with Takeda. E.J.S. has served on the advisory boards of Adaptimmune, Axio, Bayer, Celgene, Magenta, Mesoblast and Novartis. K.M.M. serves as a site investigator for receives research funding from and has served as a medical consultant for Atara Biotherapeutics, and has received research and medical education funds from and served as a medical consultant for Jazz Pharmaceuticals. All other authors declare no competing interests.

\section{Peer review information}

Nature Reviews Clinical Oncology thanks B. Geoerger and the other, anonymous, reviewer(s) for their contribution to the peer review of this work.

\section{Publisher's note}

Springer Nature remains neutral with regard to jurisdictional claims in published maps and institutional affiliations.
Supplementary information

The online version contains supplementary material available at https://doi.org/10.1038/s41571-021-00474-4.

(c) (i) Open Access This article is licensed under a Creative Commons Attribution 4.0 International License, which permits use, sharing, adaptation, distribution and reproduction in any medium or format, as long as you give appropriate credit to the original author(s) and the source, provide a link to the Creative Commons license, and indicate if changes were made. The images or other third party material in this article are included in the article's Creative Commons license, unless indicated otherwise in a credit line to the material. If material is not included in the article's Creative Commons license and your intended use is not permitted by statutory regulation or exceeds the permitted use, you will need to obtain permission directly from the copyright holder. To view a copy of this license, visit http://creativecommons.org/licenses/by/4.0/.

\section{RELATED LINKS}

Foundation for the Accreditation of Cellular Therapy:

http://www.factwebsite.org

US NIH ClinicalTrials.gov database: https://www.

clinicaltrials.gov

(C) The Author(s) 2021, corrected publication 2021 